\title{
Disagreement and Optimal Security Design
}

\author{
Juan M. Ortner and Martin C. Schmalz*
}

April 30, 2016

\begin{abstract}
What is the optimal shape of a security when the issuer and the financiers disagree about the characteristics of the asset? In our basic model, straight or callable debt is optimal. The face value increases with the market's level of optimism. Pooling multiple assets can be strictly preferred to selling optimal securities backed by the individual assets. When investors disagree amongst themselves, selling multiple tranches, e.g., including a mezzanine tranche, can be optimal. With multiple financing rounds, convertible securities commonly used in VC financing naturally emerge. The model delivers a variety of additional testable predictions.

Keywords: Disagreement, Security Design, Optimism, Overconfidence, Pooling, Behavioral Finance

JEL classification codes: G30, G32, D84, D86
\end{abstract}

* Ortner: Department of Economics, Boston University, jortner@bu.edu; Schmalz: University of Michigan Stephen M. Ross School of Business, schmalz@umich.edu. For helpful comments and discussions we would like to thank Nittai Bergman, Tilman Börgers, Markus Brunnermeier, Robin Greenwood, Naveen Khanna, Ernst Maug, Benny Moldovanu, Stefan Nagel, Uday Rajan, Adi Sunderam, Anjan Thakor, Boris Vallée, and especially Denis Gromb for very detailed comments, as well as the audience at the AEA Meetings 2016 in San Francisco, and seminar participants at Frankfurt School of Finance and Management, Universität zu Köln, and the University of Michigan. All errors are our own. 


\section{Introduction}

Which security does a firm optimally issue when firm and market agree to disagree about the firm's cash-flow distribution? Many corporate finance theorists have employed the assumption of belief disagreement between firm and investors, and in particular of optimistic issuers. For example, Heaton (2002) analyzes the investment inefficiencies that arise when a firm's manager is overly optimistic about the cash-flow distribution. More recently, Landier and Thesmar (2009) show that an entrepreneur's degree of optimism can affect the maturity of debt that he issues. However, these papers exogenously restrict the types of securities that firms issue. No paper to date has studied how differences in beliefs influence a firm's optimal security design. We study such a model and show that disagreement in beliefs can generate various commonly observed financial contracts. Perhaps most interestingly, when issuer and market disagree, selling a security backed by a pool of assets can be preferred to selling assets backed by the individual assets. Our model also explains empirical patterns in the dynamics securities issuance that are more difficult to reconcile with existing theories.

We consider an issuer who owns an asset that will pay uncertain cash-flows at a future date. To raise capital, the issuer designs a security which is backed by the asset's cash flows. Following DeMarzo and Duffie (1999), we assume the issuer discounts future cash-flows more than the market does. Such differences in discounting arise naturally e.g. when the issuer faces credit constraints. Lastly, we also assume that the issuer is more optimistic than the market about the asset's cash-flow distribution, consistent with empirical evidence (e.g., Bernardo and Welch, 2001; Malmendier et al., 2007, 2011). The issuer's problem is to design the monotonic security that maximizes her expected payoff, which is given by the market price of the security she sells plus the expected discounted retained cash-flows.

Our analysis delivers four main results. As a baseline, we show that our framework easily generates standard securities that the traditional literature generates with other frictions. We 
then turn to designs and issuance dynamics that are unique to disagreement. In particular, we first show that, under mild conditions, the optimal security takes the form of a debt contract. Second, we show that selling a security backed by a pool of several underlying assets can be strictly preferred to selling individual asset-backed securities. Third, when market participants disagree among themselves, selling separate tranches instead of a single security can be optimal. Fourth, in a model with multiple financing rounds the optimal security can be convertible preferred stock, a security commonly used in venture capital (VC) financing.

The intuition for the optimality of debt is simple - the core tradeoff is between discounting and underpricing. Specifically, because the issuer is more optimistic than the market, she finds it optimal to only sell cash-flows in the left tail of the cash-flow distribution, which the market values relatively more. By contrast, it is optimal for the issuer to retain the cash-flows in the right tail, since the market assigns a relatively low probability (and thus value) to these states. When the issuer's and market's beliefs satisfy the monotone likelihood ratio property (MLRP) the security that implements the desired trade is debt. When MLRP fails, it may be optimal to add a barrier option to the debt contract. ${ }^{1}$ This result may help explain why a large fraction of corporate bonds are callable (Duffee, 1998), ${ }^{2}$ and also rationalizes "write-off bonds" (Vallée, 2013).

We use our characterization of the optimal security to study how changes in the firm's balance sheet affect its issuance decisions. In particular, we show that pre-existing debt may lead the firm to optimally stop selling securities. This prediction contrasts with that of the traditional "pecking order" model (Myers and Majluf, 1984), in which firms never issue equity or do so only as a "last resort." Firms in our model sell equity when investors are confident. The fact that firms issue equity when stock prices and sentiment are high (e.g., Marsh, 1982;

\footnotetext{
${ }^{1}$ Excessive betting between contracting parties such as discussed in Börgers (2014) does not arise in our context as we study the design of an asset-backed security under limited liability.

${ }^{2}$ Indeed, the combination of debt plus a barrier option can be interpreted as callable debt.
} 
Baker and Wurgler, 2002; Erel et al., 2011; McLean and Zhao, 2014; Farre-Mensa, 2015) and when agreement between issuer and market is high (Dittmar and Thakor, 2007) is in line with our model's predictions, but appears inconsistent with the pecking order hypothesis.

For our second main result we consider an issuer who owns two underlying assets. ${ }^{3} \mathrm{We}$ show that, when the issuer is optimistic relative to the market, selling a security backed by the pool of assets can be preferred to selling individual asset-backed securities. Intuitively, while outside investors might be very pessimistic (relative to the issuer) about the probability of an individual asset delivering high profits, they will typically be less pessimistic about the event that at least one of several assets pays off a high return. As a result, an issuer who owns multiple assets may find it strictly optimal to combine them and sell a "senior" security backed by the pool of assets, because differences of opinion are then (literally) taken to a greater power. The following example illustrates this insight.

Example 1. Consider first an issuer who owns a single asset, which can either pay a return of 1 or a return of 0 . The market believes that the probability of the asset paying off is $\frac{1}{3}$; the issuer believes in an upside probability of $\frac{2}{3}$. The issuer discounts future cash-flows with a factor of 0.6 , whereas the market does not discount. The market is therefore willing to pay $\frac{1}{3}$ for the asset. Since the asset is worth $\frac{2}{3} \cdot 0.6=0.4$ to the issuer, she retains it.

Consider now an issuer who owns two of these assets with iid returns. The issuer's payoff from retaining the two assets is 0.8 , which is strictly larger than her payoff from selling two individual securities, each backed by an asset. Suppose instead that the issuer sells a "senior" security backed by the pool of assets that pays 1 if at least one asset pays off and zero otherwise. Investors are willing to pay $1-\left(\frac{2}{3}\right)^{2}=\frac{5}{9}$ for the security, while the issuer assigns to it a value of $\left(1-\left(\frac{1}{3}\right)^{2}\right) \cdot 0.6=\frac{8}{15}<\frac{5}{9}$. Because the issuer retains a cash-flow of 1 in the event that both assets pay off, her expected payoff from selling this security is

\footnotetext{
${ }^{3}$ For simplicity we focus on the case of two assets, although the results extend to the case in which the issuer owns several assets.
} 
$\frac{5}{9}+\left(\frac{2}{3}\right)^{2} 0.6 \approx 0.822$

We stress that differences in beliefs between the issuer and the market are crucial for pooling to be optimal. Indeed, because the issuer discounts future cash-flows more than the market, with homogenous beliefs it is always optimal for the issuer to sell the entire firm. As a result, when issuer and market share the same beliefs, the issuer is indifferent between pooling her assets or selling them as separate concerns. Moreover, our model has the feature that the optimality of pooling assets breaks down when the correlation of the underlying assets increases. This mechanism can explain the empirically observed dynamics of securitization, discussed below.

We complement the result on pooling with a result on tranching. Here, we allow different investors to hold different beliefs about the asset's cash-flow distribution. Following an intuition similar to Garmaise (2001), we show that it can be optimal to offer the market separate tranches instead of a single security. This can include retention of the most junior tranche by the issuer, as was often the case during the issuance of mortgage-backed securities in the run-up to the recent financial crisis. It can also involve the issuance of a mezzanine tranche, which is more difficult to achieve with several extant theories of optimal security design.

Finally, in a model with multiple financing rounds, convertible securities commonly used in VC financing become optimal (see, e.g., Gompers and Lerner, 2001; Kaplan and Strömberg, 2003, 2004). As before, we assume that the issuer (here: the entrepreneur) is more confident about the project's prospects than the lender (here: the VC). ${ }^{4}$ Because the entrepreneur assigns a relatively low probability to states in which performance is bad, she finds it relatively cheap to rescind cash-flows to the VC in such states. At the time of initial contracting, the entrepreneur also secures an option for a future financing round that enables her to expand the project conditional on good interim performance. ${ }^{5}$ Given her optimistic beliefs,

\footnotetext{
${ }^{4}$ See Bernardo and Welch (2001); Cooper et al. (1988); Koellinger et al. (2007); Puri and Robinson (2007) for supportive evidence.

${ }^{5}$ Our predictions do not rely on assuming that the strike of the refinancing option is determined with
} 
the entrepreneur values that option a lot. By contrast, the VC finds it cheap to write that option to the entrepreneur, because the VC finds good interim performance relatively unlikely. In addition to the optionality, the model also predicts that the VC obtains an equity stake conditional on refinancing and expanding the project at the interim stage, which allows her to break even. Importantly, the key assumption that makes the financier secure part of the upside is that both the project's required investment and its upside potential are high - in other words, the payoff profile is highly skewed. Indeed, in practice many safer entrepreneurial ventures are financed with straight (bank) debt, whereas VC financing with convertibles are used only for projects with relatively high investment needs and high potential payoffs (Cochrane, 2005). The model's mechanics are also strongly consistent with practitioners' accounts of the drivers of the use of convertibles in the financing of young firms. ${ }^{6}$

The paper proceeds as follows. Section 2 discusses the related literature. Section 3 introduces the basic model and derives the optimality of debt. Sections 4 and 5 present the results on pooling and tranching. In Section 6, convertibles naturally arise in a setting with multiple financing rounds. Section 7 concludes. All proofs are in the Appendix.

\section{Related Literature}

While this paper is the first to formally investigate the role of disagreement in optimal security design, informal mentions of the idea go back at least to Modigliani and Miller (1958). These authors write (excerpts from p. 292): "Grounds for preferring one type of

certainty at the time of initial contracting. Indeed, the fact that disagreement is reduced by learning about project quality over time is one of the key reasons for using convertible securities in early-stage financing, rather than securities that require a precise agreed-upon valuation of the project at the time of contracting.

${ }^{6}$ Entrepreneurs seeking VC funding are overoptimistic: "Guy Kawasaki, a venture capitalist, says that when an entrepreneur promises to make $\$ 50 \mathrm{~m}$ in four years he adds one year to the delivery time and divides the revenue by ten." (Economist, 2014) "Convertible debt remains an attractive way to bridge the [resulting] valuation gap." (http://www.cognitionllp.com/convertible-debt-panacea-or-pain/) 
financial structure to another still exist within the framework of our model. If the owners of a firm discovered a major investment opportunity which they felt would yield much more than [the market's discount rate], they might well prefer not to finance it via common stock. A better course would be to finance the project initially with debt. Still another possibility might be to [issue] a convertible debenture."

Because there is open disagreement in our model rather than asymmetric information between issuer and market, our paper is sharply distinguished from contributions that rationalize particular securities, including the predominance of debt, with adverse selection or an informational advantage of insiders over the market (Myers and Majluf, 1984; Innes, 1990; Nachman and Noe, 1994), from papers that point out the fragility of the same "pecking order" result to the choice of specific off-equilibrium beliefs (Noe, 1988), to which agent is privately informed (Inderst and Mueller, 2006; Axelson, 2007), and to particular distributional assumptions (e.g., Nachman and Noe, 1990, 1994; Fulghieri et al., 2013). ${ }^{7}$ Because differences in beliefs are common knowledge in our model, the financier does not have to screen borrowers based on their level of optimism as in Manove and Padilla (1999). Similarly, the pooling results in DeMarzo (2005) rely on asymmetric information whereas ours don't; hence, our result is robust to the critique that informational asymmetries oftentimes are not overcome by pooling (Arora et al., 2013). Stein (1992) uses adverse selection to derive convertible debt. By contrast, our "convertibles" result uses only disagreement.

Our theory also makes no use of moral hazard as a driver of the optimal security anywhere. In particular, the alignment of incentives plays no role in generating convertibles; this is in contrast to earlier contributions by Green (1984); Admati and Pfleiderer (1994); Schmidt (2003); Cornelli and Yosha (2003). ${ }^{8}$ Lastly, investors in our model do not suffer from limited

\footnotetext{
${ }^{7}$ In our model, the only key assumption that is necessary for the main results is that the issuer is more optimistic than the issuer about the right tail of the cash flow distribution.

${ }^{8}$ For other models linking moral hazard and security design, see Bergemann and Hege (1998); Winton and Yerramilli (2008); Antic (2014); Hébert (2014).
} 
channel capacity, which can render debt and pooling optimal (Yang, 2013), and can also explain the use of convertibles in venture capital financing (Yang and Zeng, 2015).

Several previous papers in corporate finance invoke differences in beliefs to explain investment, financing, payout and capital structure choices (e.g., Heaton (2002); Coval and Thakor (2005); Dittmar and Thakor (2007); Landier and Thesmar (2009)). ${ }^{9}$ However, these papers do not study optimal security design in the sense of Allen and Gale (1988), since they assume a constrained state space and/or contracting space. ${ }^{10}$ An exception is Garmaise (2001), who shows that tranching can be optimal in a model in which there is disagreement among investors and in which the prices of securities are determined through a first price auction. In contrast to Simsek (2013a,b) and Brunnermeier et al. (forthcoming), the disagreement in our model is not between different sets of traders, but between issuer and market.

In sum, previous papers have investigated the effect of disagreement on financial decisions; others have investigated the effect of informational and other frictions on optimal security design. Our paper contributes to the intersection of these literatures by providing a full and formal analysis of the effect of disagreement on optimal security design. The insight that disagreement can generate rich predictions that previous models generated with other frictions is important, because different empirical proxies capture these different frictions. The paper hence contributes a starting point for a more nuanced empirical investigation of precisely which securities firms issue, and why. Moreover, our comparatively simple model of disagreement can generate a variety of securities for which the literature thus far has employed separate models. Lastly, the model makes several new empirical predictions. We

\footnotetext{
${ }^{9}$ See also Hackbarth (2008); Boot and Thakor (2011); Gervais et al. (2011); Bayar et al. (2011); Thakor and Whited (2011); Huang and Thakor (2013); Adam et al. (2014); Bayar et al. (forthcoming); Geanakoplos (2010)

${ }^{10}$ Disagreement is related to outcome variables other than capital structure by Boot et al. $(2006,2008)$, Adrian and Westerfield (2009), Dicks and Fulghieri (2015) and Shleifer et al. (2015). The observation that the optimal securities can be sold also to employees relates our paper to Hellman and Puri (2000), Oyer and Schaefer (2005), and Bergman and Jenter (2007).
} 
discuss those in what follows.

\section{Basic Model}

\subsection{Payoffs, Beliefs, and Objectives}

At date $t=0$, an issuer owns a risky asset yielding state-contingent payoffs at date $t=1$. There is a finite set of possible states of nature $S=\{1, . ., K\}$ at $t=1$, and the asset pays an amount $X_{s} \in \mathbb{R}_{+}$in state $s \in S .{ }^{11}$ We assume that $X_{s}>0$ for all $s \in S$ and that there exists at least one pair of states $s, s^{\prime} \in S$ such that $X_{s} \neq X_{s^{\prime}}$. Without loss of generality, we order the states so that $X_{1} \leq X_{2} \leq \ldots \leq X_{K}$.

The issuer has to design a security $F \in \mathbb{R}_{+}^{K}$ backed by the cash-flows $X=\left(X_{s}\right)_{s \in S}$ to sell it in the market. Thus, security $F$ must be such that $0 \leq F_{s} \leq X_{s}$ for all $s \in S$. Let $\pi^{I}$ be the probability distribution over $S$ that represents the issuer's beliefs. We assume that $\pi_{s}^{I}>0$ for all $s \in S$. Following DeMarzo and Duffie (1999) we assume that the issuer discounts retained cash-flows at a rate that is higher than the market rate (which is normalized to 1 ). ${ }^{12}$ After selling the security, the issuer retains $X-F$ of the cash-flows generated by the asset. Thus, the issuer attaches a value of $\delta \sum_{s \in S} \pi_{s}^{I}\left(X_{s}-F_{s}\right)$ to retained cash-flows, where $\delta \in(0,1)$ is the issuer's discount rate. The payoff of an issuer who sells to the market a security $F$ at a price $p$ is then given by $p+\delta \sum_{s \in S} \pi_{s}^{I}\left(X_{s}-F_{s}\right)$.

We assume that the market has different beliefs about the cash-flow distribution of the underlying asset than the issuer. Let $\pi^{M}$ be the probability distribution over $S$ that describes the market's beliefs, with $\pi_{s}^{M}>0$ for all $s \in S$. We assume that the issuer is more optimistic

\footnotetext{
${ }^{11}$ The assumption that states are finite is for simplicity. Our results are robust to having a continuum of states.

${ }^{12}$ The assumption that the issuer discounts future cash-flows at a higher rate than the market is a metaphor, for example for a situation in which the issuer has some profitable investment opportunity. Also, the assumption will hold if the issuer faces credit constraints or, as in the case of financial entities, minimumcapital requirements.
} 
than the market, so that $\pi^{I}$ first-order stochastically dominates $\pi^{M} \cdot{ }^{13}$

The price that the market is willing to pay for security $F$ is $p(F):=\sum_{s \in S} \pi_{s}^{M} F_{s}$. Overall, the issuer's payoff from selling security $F$ is

$$
U(F):=p(F)+\delta \sum_{s \in S} \pi_{s}^{I}\left(X_{s}-F_{s}\right)
$$

Definition 1. Say that security $F$ is monotonic if $F_{s}$ and $X_{s}-F_{s}$ are both increasing in $s$.

We will assume that the issuer is restricted to sell monotonic securities. The restriction to monotonic securities is standard in the literature of optimal security design; see, for instance, Innes (1990); DeMarzo and Duffie (1999). ${ }^{14}$ In Appendix B we show how our results change when we relax this restriction.

Let $\mathcal{F}$ be the set of feasible securities

$$
\mathcal{F}:=\left\{F \in \mathbb{R}^{K}: 0 \leq F_{s} \leq X_{s} \forall s \in S \text { and } F \text { is monotonic }\right\}
$$

The issuer's problem is to find the security $F$ within the set of feasible securities $\mathcal{F}$ that maximizes her payoff, taking the market's beliefs as given. Formally, the issuer's problem is

$$
\sup _{F \in \mathcal{F}} U(F)
$$

\footnotetext{
${ }^{13}$ There is an alternative interpretation for the differences in beliefs in our model: if we interpret $\pi^{I}$ and $\pi^{M}$ as risk-neutral probabilities, then $\pi^{I}$ and $\pi^{M}$ will be different whenever issuer and market have different preferences, even if they share the same beliefs over $S$. If issuer and market are expected utility maximizers and share the same beliefs over $S$, then the issuer's risk-neutral probabilities $\pi^{I}$ will first-order stochastically dominate the market's risk-neutral probabilities $\pi^{M}$ only under the assumption that the issuer is less riskaverse than the market. Because the standard assumption is that the risk-bearing capacity of the market is larger than that of the issuer, we find the heterogeneous-beliefs interpretation more adequate.

${ }^{14} \mathrm{As}$ is well known, this assumption can be microfounded with a moral hazard problem. To avoid high payments implied by a non-increasing security, the issuer could easily inflate cash flows, e.g., by borrowing privately, and thus decrease payments to the investor.
} 


\subsection{Optimal Security Design with Divergent Beliefs}

In this section we present the solution to problem (1). We introduce additional notation before presenting our results. For any $s \in S$, let $A_{s}:=\{s, s+1, \ldots, K\}$ be the event that the asset yields cash-flows weakly larger than $X_{s}$. For all $s \in S$, let $\pi^{I}\left(A_{s}\right):=\sum_{s^{\prime} \geq s} \pi_{s^{\prime}}^{I}$ and $\pi^{M}\left(A_{s}\right):=\sum_{s^{\prime} \geq s} \pi_{s^{\prime}}^{M}$ be, respectively, the probability that the issuer and market assign to event $A_{s}$. The assumption that $\pi^{I}$ first-order stochastically dominates $\pi^{M}$ implies that $\pi^{I}\left(A_{s}\right) \geq \pi^{M}\left(A_{s}\right)$ for all $s \in S$. The following result characterizes the optimal security. In what follows, we use the convention that $F_{0}=X_{0}=0$ for all $F \in \mathcal{F}$.

Proposition 1. The optimal security is described by:

$$
\forall s \in S, \quad F_{s}= \begin{cases}F_{s-1}+X_{s}-X_{s-1} & \text { if } \pi^{M}\left(A_{s}\right) \geq \delta \pi^{I}\left(A_{s}\right), \\ F_{s-1} & \text { if } \pi^{M}\left(A_{s}\right)<\delta \pi^{I}\left(A_{s}\right) .\end{cases}
$$

The key value that determines the shape of the optimal security at each state $s$ is the ratio between $\pi^{M}\left(A_{s}\right)$ and $\pi^{I}\left(A_{s}\right)$; i.e., the ratio of the probability that the market and issuer assign to profits being larger than $X_{s}$. If $\frac{\pi^{M}\left(A_{s}\right)}{\pi^{I}\left(A_{s}\right)} \geq \delta$, the optimal security $F$ pays the largest possible amount in state $s$; if $\frac{\pi^{M}\left(A_{s}\right)}{\pi^{I}\left(A_{s}\right)}<\delta$, the optimal security pays the least possible amount (in both cases, subject to the constraint that $F$ is monotonic). That is, for each state, the issuer simply asks herself it the cash flow that obtains in that state is more valuable to herself or to the market, and retains or sells that cash flow accordingly.

The following corollaries immediately follow.

Corollary 1. If $\pi^{M}\left(A_{s}\right) \geq \delta \pi^{I}\left(A_{s}\right)$ for all $s \in S$, then it is optimal to sell the entire firm; i.e., $F_{s}=X_{s}$ for all $s \in S$. 
Corollary 2. If $\pi^{M}\left(A_{s}\right)<\delta \pi^{I}\left(A_{s}\right)$ for all $s>1$, then risk-less debt is an optimal security; i.e., $F_{s}=X_{1}$ for all $s \in S$.

Corollary 3. Suppose there exists $k \in S \backslash\{1, K\}$ such that $\pi^{M}\left(A_{s}\right) \geq \delta \pi^{I}\left(A_{s}\right)$ if and only if $s \leq k$. Then, risky debt with face value $X_{k}$ is an optimal security; i.e., $F_{s}=\min \left\{X_{s}, X_{k}\right\}$ for all $s \in S$.

By Corollaries 1, 2 and 3, the optimal security can take the form of a debt contract. The face value of the debt contract ranges from the lowest state, which makes risk-less debt the optimal security, to risky debt with face value $X_{k} \in\left(X_{1}, X_{K}\right)$, to risky debt that always defaults (because the face value is equal to the highest possible cash-flow), which can be interpreted as an equity issuance.

In sum, our model predicts that firms issue debt with a lower face value when there is more belief disagreement between issuers and markets. When the market is extremely pessimistic, the firm will issue only risk-free debt. (Once that option is exhausted, it stops issuance altogether, as we show below.) By contrast, the issuer sells the whole firm when the market is optimistic and there is less disagreement.

This prediction is strongly consistent with the timing of securities issuances to meet market sentiment (e.g., Marsh (1982); Baker and Wurgler (2002), and in particular Dittmar and Thakor (2007)). At the same time, our prediction is in stark contrast to several theories of security design based on asymmetric information. Most prominently, the traditional "pecking order" hypothesis holds that firms issue equity only as a "last resort" (e.g., Myers, 1984) hence, only the worst firms that have run out of other options issue equity. Contrasting that prediction is the empirical evidence, which indicates that firms issue equity also (and indeed predominantly) when not in financial distress (Frank and Goyal, 2003; Fama and French, 2005). The empirical evidence is arguably more consistent with the disagreement prediction that the relative optimism of investors versus firms drives issuance decisions: Farre-Mensa 
(2015) analyses firms that are hit with negative cash-flow shocks and thus face a need to issue securities (a decrease in $\delta$ in our model), and shows that firms whose stock is overvalued issue equity, whereas undervalued firms issue debt. Similar in spirit, Erel et al. (2011) and McLean and Zhao (2014) find that equity issuance is cyclical and higher amid positive investor sentiment, whereas firms turn to issuing safer securities during market downturns.

\section{Optimality of debt under MLRP}

Suppose that $\pi^{I}$ and $\pi^{M}$ are such that $\frac{\pi_{s}^{I}}{\pi_{s}^{M}}$ is increasing in $s$; i.e., $\frac{\pi_{s}^{I}}{\pi_{s}^{M}}$ satisfies the Monotone Likelihood Ratio Property (MLRP). Note that $\frac{\pi_{s}^{I}}{\pi_{s}^{M}}$ increasing in $s$ implies that $\frac{\pi^{M}\left(A_{s}\right)}{\pi^{I}\left(A_{s}\right)}$ is decreasing in $s$. In this case, if $\delta \in\left(\frac{\pi^{M}\left(A_{K}\right)}{\pi^{I}\left(A_{K}\right)}, \frac{\pi^{M}\left(A_{2}\right)}{\pi^{I}\left(A_{2}\right)}\right]$, the optimal security $F$ is such that $F_{s}=$ $\min \left\{X_{s}, X_{k}\right\}$ for some $k \in S \backslash\{1, K\}$. The following corollary summarizes this discussion.

Corollary 4. If $\frac{\pi_{s}^{I}}{\pi_{s}^{M}}$ satisfy $M L R P$ and $\delta \in\left(\frac{\pi^{M}\left(A_{K}\right)}{\pi^{I}\left(A_{K}\right)}, \frac{\pi^{M}\left(A_{2}\right)}{\pi^{I}\left(A_{2}\right)}\right]$, there exists $k \in S \backslash\{1, K\}$ such that debt with face value $X_{k}$ is optimal.

\section{Debt plus barrier options}

The following corollary to Proposition 1 shows that securities other than straight debt can be optimal.

Corollary 5. Suppose that there exists $k, k^{\prime} \in S$, with $k+1<k^{\prime}$, such that $\pi^{M}\left(A_{s}\right) \geq \delta \pi^{I}\left(A_{s}\right)$ if and only if either $s \leq k$ or $s=k^{\prime}$. Then, the optimal security is

$$
F_{s}= \begin{cases}\min \left\{X_{s}, X_{k}\right\} & \text { if } s<k^{\prime} \\ X_{k^{\prime}}-X_{k^{\prime}-1}+X_{k} & \text { if } s \geq k^{\prime}\end{cases}
$$

The security in Corollary 5 can be thought of as a combination of debt with face value $X_{k}$ plus a barrier option that pays $X_{k^{\prime}}-X_{k^{\prime}-1}$ in the event that the asset yields a payoff 
weakly larger than $X_{k^{\prime}}{ }^{15}$ Such an event could be the corporation calling the bond, which is typically associated with a positive additional cash flow to bondholders. While the prediction of callable debt is rare in the theoretical literature, a large fraction of real-world corporate bonds is indeed callable (Duffee, 1998). Such a security can also be interpreted as a write-off bond: the face value, and thus the payoff, of such contracts is discontinuously higher when cash-flows exceed a certain threshold (Vallée, 2013).

\subsection{Pre-existing Debt}

We now extend our baseline setting to consider the problem of an issuer who has senior debt outstanding that is backed by the cash-flows that her asset will generate, and who is considering to issue a new security backed by the remaining cash-flows. Formally, suppose the issuer has debt outstanding with face value $D<X_{K}$. The issuer wants to design a security $F \in \mathbb{R}_{+}^{K}$ to sell to the market, with $F$ backed by the remaining cash-flows she owns; i.e., $F$ such that $0 \leq F_{s} \leq X_{s}-\min \left\{X_{s}, D\right\}$ for all $s \in S$. As before, we restrict the issuer to design securities such that both the cash-flows that she pays and the cash-flows that she retains are monotone in the underlying asset's cash-flows; that is, securities $F$ such that $F_{s}$ and $X_{s}-F_{s}-\min \left\{X_{s}, D\right\}$ are increasing in $s$. Let $\mathcal{F}_{D}$ denote the set of feasible securities; i.e., $\mathcal{F}_{D}:=\left\{F \in \mathbb{R}^{K}: 0 \leq F_{s} \leq X_{s}-\min \left\{X_{s}, D\right\} \forall s \in S\right.$ and $F_{s}$ and $X_{s}-F_{s}-\min \left\{X_{s}, D\right\}$ are increasing in $s\}$. The issuer's problem is

$$
\sup _{F \in \mathcal{F}_{D}} U_{D}(F)
$$

\footnotetext{
${ }^{15}$ In their model with asymmetric information, Nachman and Noe (1994) also show that securities similar to the one in Corollary 5 can be optimal.
} 
where for any $F \in \mathcal{F}_{D}$,

$$
U_{D}(F):=\sum_{s \in S} \pi_{s}^{M} F_{s}+\delta \sum_{s \in S} \pi_{s}^{I}\left(X_{s}-\min \left\{X_{s}, D\right\}-F_{s}\right)
$$

Let $s_{D}=\max \left\{s \in S: X_{s} \leq D\right\}$, and note that any security $F \in \mathcal{F}_{D}$ must be such that $F_{s}=0$ for all $s \leq s_{D}$. The next proposition shows that the issuer may cease to issue any security when she has pre-existing debt outstanding.

Proposition 2. Suppose the issuer already has debt outstanding with face value D. Then, the security that solves (2) is described by

$$
\forall s \in S, \quad F_{s}= \begin{cases}0 & \text { if } s \leq s_{D} \\ F_{s-1}+X_{s}-X_{s-1} & \text { if } \pi^{M}\left(A_{s}\right) \geq \delta \pi^{I}\left(A_{s}\right) \text { and } s>s_{D}, \\ F_{s-1} & \text { if } \pi^{M}\left(A_{s}\right)<\delta \pi^{I}\left(A_{s}\right) \text { and } s>s_{D} .\end{cases}
$$

If $\pi^{M}\left(A_{s}\right)<\delta \pi^{I}\left(A_{s}\right)$ for all $s>s_{D}$, the solution to (2) is $F_{s}=0$ for all $s \in S$.

This result shows that the firm in our model may stop the issuance of all securities when it becomes over-levered. This prediction contrasts with that of informational theories of security design as well as with tradeoff models, in which the firm may start to issue equity instead of debt when it has preexisting debt. These opposing predictions suggest a plausible way of telling these theories apart empirically. The existing evidence supports the prediction made here: Erel et al. (2011) show that low market sentiment can indeed lead firms not only to stop equity issuances but to not access credit markets at all. 


\section{Pooling}

This section shows how an issuer who has more optimistic beliefs than the market can strictly benefit from pooling different assets and designing a security backed by the cashflows generated by the pool. We begin by illustrating this by means of a simple example.

\subsection{A Simple Example}

Suppose the issuer owns an asset that can yield cash-flows of $X_{1}>0$ or $X_{2}>X_{1}$. Let $\pi^{I} \in(0,1)$ and $\pi^{M} \in(0,1)$ be, respectively, the probability the issuer and market assigns to the asset yielding cash-flows $X_{1}$. As above, we assume that the issuer is more optimistic than the market, so $\pi^{I}<\pi^{M}$.

Consider first the problem of designing a security backed by the asset described above. By Proposition 1, an optimal security $F$ has $F_{1}=X_{1}$ and has $F_{2}=X_{1}$ if $\delta\left(1-\pi^{I}\right)>1-\pi^{M}$ and $F_{2}=X_{2}$ if $\delta\left(1-\pi^{I}\right)<1-\pi^{M}$. The market price of security $F$ is $p(F)=\pi^{M} X_{1}+\left(1-\pi^{M}\right) F_{2}$.

Consider next the case in which the issuer has two identical assets, $X^{1}$ and $X^{2}$, with iid cash-flows. Each of the assets can produce cash-flows in $\left\{X_{1}, X_{2}\right\}$. Assume that $\pi^{M}>$ $1-\delta\left(1-\pi^{I}\right)$, so that the optimal security backed by asset $X^{i}$ has $F_{s}=X_{1}$ for $s=1,2$. The issuer's profits from selling two securities separately are

$$
2 p(F)+2 \delta\left(1-\pi^{I}\right)\left(X_{2}-F_{2}\right)=2 X_{1}+2 \delta\left(1-\pi^{I}\right)\left(X_{2}-X_{1}\right) .
$$

Suppose instead that the issuer pools the two assets and sells a single security backed by the pool. Let $Y=X^{1}+X^{2}$, let $F_{Y}=\min \left\{Y, X_{1}+X_{2}\right\}$. The market-price of security $F_{Y}$ is $p\left(F_{Y}\right)=\left(\pi^{M}\right)^{2} 2 X_{1}+\left(1-\left(\pi^{M}\right)^{2}\right)\left(X_{1}+X_{2}\right)$, and the issuer's payoff from selling $F_{Y}$ is

$$
p\left(F_{Y}\right)+\delta\left(1-\pi^{I}\right)^{2}\left(2 X_{2}-X_{2}-X_{1}\right)=2 X_{1}+\left(1-\left(\pi^{M}\right)^{2}+\delta\left(1-\pi^{I}\right)^{2}\right)\left(X_{2}-X_{1}\right)
$$


Comparing equations (3) and (4), the issuer strictly prefers to pool the assets and sell security $F_{Y}$ if $\pi^{M}<\sqrt{1-\delta\left(1-\left(\pi^{I}\right)^{2}\right)}$. Therefore, for $\pi^{M} \in\left(1-\delta\left(1-\pi^{I}\right), \sqrt{1-\delta\left(1-\left(\pi^{I}\right)^{2}\right)}\right)$, pooling is strictly optimal for the issuer. Intuitively, the market is relatively less pessimistic about the event that one of the two assets yields a cash-flow of $X_{1}$. By pooling the two assets, the issuer is able to design a security that pays off a high return precisely when this event occurs. Note that this simple example clarifies why changes in belief divergence between issuers and the market should relate to the time-series variation in the issuance of asset-backed securities (Chernenko et al., 2013).

\subsection{General Framework}

We now present a general result. Consider an issuer who owns two assets, $X^{1}$ and $X^{2}$, with iid returns. ${ }^{16}$ Let $S=\{1, \ldots, K\}$ and let $\left\{X_{s}\right\}_{s \in S}$ be the possible cash-flow realizations of asset $X^{i}$. Without loss of generality we assume that $X_{1} \leq X_{2} \leq \ldots \leq X_{K}$.

Let $\pi^{I}$ and $\pi^{M}$ be two probability distributions over $S$, with $\pi^{I}$ and $\pi^{M}$ representing, respectively, the beliefs of issuer and market. We assume that the issuer is more optimistic than the market, so $\pi^{I}$ first-order stochastically dominates $\pi^{M}$. The issuer discounts future profits at rate $\delta<1$, whereas the market discounts future profits at rate 1 . Let $\hat{S}=S \times S$. For any security $F \in \mathbb{R}^{|\hat{S}|}$ and any $\left(s, s^{\prime}\right) \in \hat{S}$, let $F_{s, s^{\prime}}$ be the amount that the security pays when assets $X^{1}$ and $X^{2}$ yield cash-flows $X_{s}$ and $X_{s^{\prime}}$, respectively. The following definition generalizes Definition 1 to the current environment:

Definition 2. Say that security $F$ backed by asset $Y=X^{1}+X^{2}$ is $X^{1} X^{2}$-monotonic if:

(i) for all $s^{\prime} \in S, F_{s, s^{\prime}}$ and $X_{s}+X_{s^{\prime}}-F_{s, s^{\prime}}$ are increasing in $s$, and

(ii) for all $s \in S, F_{s, s^{\prime}}$ and $X_{s}+X_{s^{\prime}}-F_{s, s^{\prime}}$ are increasing in $s^{\prime}$.

\footnotetext{
${ }^{16}$ We focus on the case of two assets for simplicity. The results can be extended to the case of $n>2$ assets.
} 
Recall that $\hat{S}=S \times S$, and let $\mathcal{F}_{Y}$ be the set of feasible securities:

$$
\mathcal{F}_{Y}:=\left\{F \in \mathbb{R}^{|\hat{S}|}: 0 \leq F_{s, s^{\prime}} \leq X_{s}+X_{s^{\prime}} \forall\left(s, s^{\prime}\right) \in \hat{S} \text { and } F \text { is } X^{1} X^{2} \text {-monotonic }\right\}
$$

The price that the market is willing to pay for security $F \in \mathcal{F}_{Y}$ is $p_{Y}(F):=\sum_{s \in S} \sum_{s^{\prime} \in S} \pi_{s}^{M} \pi_{s^{\prime}}^{M} F_{s, s^{\prime}}$. The issuer's payoff from selling security $F \in \mathcal{F}_{Y}$ is

$$
U_{Y}(F):=p_{Y}(F)+\delta \sum_{s \in S} \sum_{s^{\prime} \in S} \pi_{s}^{I} \pi_{s^{\prime}}^{I}\left(X_{s}+X_{s^{\prime}}-F_{s, s^{\prime}}\right)
$$

The optimal security backed by the pool $Y=X^{1}+X^{2}$ solves

$$
\sup _{F \in \mathcal{F}_{Y}} U_{Y}(F)
$$

Let $F^{*} \in \mathcal{F}$ be the optimal security backed by a single asset $X^{i}$. The issuer's payoff from selling two individual securities, each backed by one asset, is $2 U\left(F^{*}\right)$. The following result provides sufficient conditions under which $\sup _{F \in \mathcal{F}_{Y}} U_{Y}(F)>2 U\left(F^{*}\right)$. As before, for each $s \in S$ let $A_{s}=\{s, s+1, \ldots, K\}$ be the event that an asset pays weakly more than $X_{s}$.

Proposition 3. Pooling can be optimal. Suppose there exists $k \in S \backslash\{K\}$ such that

(i) $\pi^{M}\left(A_{s}\right) \geq \delta \pi^{I}\left(A_{s}\right)$ if and only if $s \leq k$, and

(ii) $\frac{\pi^{M}\left(A_{k+1}\right)}{\delta \pi^{I}\left(A_{k+1}\right)}>\frac{2-\pi^{I}\left(A_{k+1}\right)}{2-\pi^{M}\left(A_{k+1}\right)}$.

Then, $\sup _{F \in \mathcal{F}_{Y}} U_{Y}(F)>2 U\left(F^{*}\right)$.

Proposition 3 generalizes the example of Section 4.1 to the current setting. As in the example, pooling the assets allows the issuer to design securities that are better tailored to the relatively pessimistic beliefs of investors. In turn, this makes the issuer strictly better off than selling the two securities as separate concerns. 
We stress that the restrictions in Definition 2 do not necessarily imply that security $F \in \mathcal{F}_{Y}$ will be monotonic in $Y=X^{1}+X^{2}$; that is, $F(Y)$ and $Y-F(Y)$ need not be increasing in $Y$. To restrict attention to securities that are monotonic in $Y$, let $\tilde{S}=\left\{1, \ldots, k^{2}\right\}$ be a relabeling of the states in $\hat{S}=S \times S$ such that $Y_{1} \leq Y_{2} \leq \ldots \leq Y_{k^{2}}$. Let $\tilde{\pi}^{I}$ and $\tilde{\pi}^{M}$ be, respectively, the issuer's and market's beliefs over $\tilde{S}$ (which are derived from $\pi^{I}$ and $\pi^{M}$ ). Since $\pi^{I}$ first-order stochastically dominates $\pi^{M}$, it follows that $\tilde{\pi}^{I}$ first-order stochastically dominates $\tilde{\pi}^{M}$. With this notation, security $F$ backed by asset $Y$ is monotonic in $Y$ if $F_{\tilde{s}}$ and $Y_{\tilde{s}}-F_{\tilde{s}}$ are both increasing in $\tilde{s}$. Let

$$
\mathcal{F}_{Y}^{*}:=\left\{F \in \mathbb{R}^{|\tilde{S}|}: 0 \leq F_{s} \leq Y_{s} \forall s \in \tilde{S} \text { and } F \text { is monotonic }\right\}
$$

When restricted to issue securities in $\mathcal{F}_{Y}^{*}$, the issuer's problem is

$$
\sup _{F \in \mathcal{F}_{Y}^{*}} U_{Y}(F)
$$

Note that the solution to (6) is characterized by Proposition 1 (using beliefs $\tilde{\pi}^{I}$ and $\tilde{\pi}^{M}$ instead of $\pi^{I}$ and $\pi^{M}$ ). With the solution to (6) in hand, one can easily check if $\sup _{F \in \mathcal{F}_{Y}^{*}} U_{Y}(F)>$ $2 U\left(F^{*}\right) \cdot{ }^{17}$

We conclude this section by discussing how our results extend to the case in which the underlying assets' returns are not iid. In Appendix C we generalize the example in Section 4.1 to the case of non-zero correlations and characterize the set of parameters for which pooling is optimal. Consistent with the time-series variation in the issuance of asset-backed securities (Chernenko et al., 2013), pooling remains optimal as long as the correlation between the underlying assets is not too high.

Finally, our model assumes that issuer and market disagree about the return distribution

\footnotetext{
${ }^{17}$ Note that the example in Section 4.1 already shows that $\sup _{F \in \mathcal{F}_{Y}^{*}} U_{Y}(F)>2 U\left(F^{*}\right)$ is possible, since the pooled security in that example is monotonic in $Y$.
} 
of each of the underlying assets, but agree on the correlation between these assets. We stress that disagreement about the correlation in the assets' return can strengthen the investor's incentives for pooling. To see this, consider again the setting in Section 4.1. Suppose that the market believes that the two assets are $i i d$, while the issuer believes that the two assets are perfectly correlated. Assume again that $\pi^{M}>1-\delta\left(1-\pi^{I}\right)$, so that the optimal security backed by asset $X^{i}$ has $F_{s}=X_{1}$ for $s=1,2$. The issuer's profits from selling the securities separately are given by (3), while her payoff from selling security $F_{Y}=\min \left\{Y, X_{1}+X_{2}\right\}$ now is

$$
p\left(F_{Y}\right)+\delta\left(1-\pi^{I}\right)\left(X_{2}-X_{1}\right)=2 X_{1}+\left(1-\left(\pi^{M}\right)^{2}+\delta\left(1-\pi^{I}\right)\right)\left(X_{2}-X_{1}\right),
$$

where $p\left(F_{Y}\right)=\left(\pi^{M}\right)^{2} 2 X_{1}+\left(1-\left(\pi^{M}\right)^{2}\right)\left(X_{1}+X_{2}\right)$ is the price that the market is willing to pay for security $F_{Y}$. Comparing (7) with (3), pooling is strictly optimal whenever $\pi^{M} \in$ $\left(1-\delta\left(1-\pi^{I}\right), \sqrt{1-\delta\left(1-\pi^{I}\right)}\right)$.

\section{Tranching}

We now extend our basic framework in Section 3 to allow for heterogeneity of beliefs among investors. We show that it may be optimal to issue multiple tranches, thus complementing our result on pooling.

As in Section 3, we consider an issuer who owns an asset which will yield state-contingent payoffs at date $t=1$. Let $\left\{X_{s}\right\}_{s \in S}$ be the possible cash-flow realizations of the asset, where $S=\{1, \ldots, K\}$ is the set of possible states of nature. Let $\pi^{I}$ be a probability distribution over $S$ representing the issuer's beliefs about the possible state realizations. The issuer discounts future cash-flows at rate $\delta<1$, while market participants discount them at rate 1 .

There are two types of investors in the market, $\tau=t_{1}, t_{2}$. The two types of investors 
differ in their beliefs about the cash-flow distribution of the asset that the issuer owns. Let $\pi^{\tau}$ be a probability distribution over $S$ representing the beliefs of investors of type $\tau$. We assume that the issuer is more optimistic than both types of investors: for $\tau=t_{1}, t_{2}, \pi^{I}$ first-order stochastically dominates $\pi^{\tau}$. To keep the analysis simple, we further assume that for $\tau=t_{1}, t_{2}$, there exists $s_{\tau} \in S \backslash\{1, K\}$ with $s_{t_{1}} \neq s_{t_{2}}$ such that $\pi^{\tau}\left(A_{s}\right) \geq \delta \pi^{I}\left(A_{s}\right)$ if and only if $s \leq s_{\tau}$. By Corollary 3, this implies that the optimal security for the issuer when facing a group investors with beliefs $\pi^{\tau}$ is risky debt with face value $X_{s_{\tau}}$. Without further loss of generality, assume that $s_{t_{1}}<s_{t_{2}}$.

For any security $F \in \mathcal{F}$, the price that investors of type $\tau$ are willing to pay is $p^{\tau}(F):=$ $\sum_{s} \pi_{s}^{\tau} F_{s}$. The profits that the issuer gets from selling security $F$ to investors of group $\tau$ are $U^{\tau}(F):=p^{\tau}(F)+\delta \sum_{s} \pi_{s}^{I}\left(X_{s}-F_{s}\right)$. For $\tau=t_{1}, t_{2}$, let $F_{s}^{\tau}=\min \left\{X_{s}, X_{s_{\tau}}\right\}$. Note that $F_{s}^{\tau}$ solves $\sup _{F \in \mathcal{F}} U^{\tau}(F)$. If the issuer designs a single security $F \in \mathcal{F}$ to sell to the market, the largest payoff she can obtain is $\max \left\{U^{t_{1}}\left(F^{t_{1}}\right), U^{t_{2}}\left(F^{t_{2}}\right)\right\}$.

Consider next an issuer who designs two different securities, $F^{1}$ and $F^{2}$, both of them backed by the cash-flows generated by asset $X_{s}$; i.e., with $0 \leq F_{s}^{1}+F_{s}^{2} \leq X_{s}$ for all $s \in S$.

Definition 3. Say that securities $F^{1}$ and $F^{2}$ are jointly monotonic if $F_{s}^{1}$ and $F_{s}^{2}$ are increasing in $s$ and if $X_{s}-F_{s}^{1}-F_{s}^{2}$ is increasing in $s$.

Let $\mathcal{F}^{T}$ be the set of feasible securities

$$
\mathcal{F}^{T}:=\left\{F^{1}, F^{2} \in \mathbb{R}_{+}^{K}: 0 \leq F_{s}^{1}+F_{s}^{2} \leq X_{s} \forall s \in S \text { and } F^{1} \text { and } F^{2} \text { are jointly monotonic }\right\}
$$

For any $F^{1}, F^{2} \in \mathcal{F}^{T}$, let

$$
U^{T}\left(F^{1}, F^{2}\right):=\max \left\{p^{t_{1}}\left(F^{1}\right), p^{t_{2}}\left(F^{1}\right)\right\}+\max \left\{p^{t_{1}}\left(F^{2}\right), p^{t_{2}}\left(F^{2}\right)\right\}+\delta \sum_{s} \pi_{s}^{I}\left(X_{s}-F_{s}^{1}-F_{2}^{2}\right)
$$

be the payoff that the issuer obtains from selling this pair of securities to the market. The 
issuer's problem is

$$
\sup _{\left(F^{1}, F^{2}\right) \in \mathcal{F}^{T}} U^{T}\left(F^{1}, F^{2}\right)
$$

Our goal is to identify sufficient conditions on the investors' beliefs under which offering two tranches is strictly better than selling one security; i.e., under which $\sup _{\left(F^{1}, F^{2}\right) \in \mathcal{F}^{T}} U^{T}\left(F^{1}, F^{2}\right)>$ $\max \left\{U^{t_{1}}\left(F^{t_{1}}\right), U^{t_{2}}\left(F^{t_{2}}\right)\right\}$.

Assumption 1. There exists $\hat{s} \in S$ with $\hat{s}+1 \leq s_{t_{1}}$ such that $\sum_{s \leq s^{\prime}} \pi_{s}^{t_{1}}<\sum_{s \leq s^{\prime}} \pi_{s}^{t_{2}}$ for all $s^{\prime} \leq \hat{s}$ and $\sum_{s \leq s^{\prime}} \pi_{s}^{t_{1}} \geq \sum_{s \leq s^{\prime}} \pi_{s}^{t_{2}}$ for $s^{\prime} \geq \hat{s}+1$, with strict inequality for $s^{\prime} \neq K$.

Assumption 1 states that the c.d.f's $\Pi_{s}^{\tau}:=\sum_{s \leq s^{\prime}} \pi_{s}^{\tau}$ of the two types of investors cross at exactly one point. When the two types of investors assign the same value to the underlying asset (i.e., when $\sum_{s} \pi_{s}^{t_{1}} X_{s}=\sum_{s} \pi_{s}^{t_{2}} X_{s}$ ), Assumption 1 implies that $\pi^{t_{1}}$ second-order stochastically dominates $\pi^{t_{2}}$; i.e., type $t_{2}$ investors perceive the asset to be more risky than type $t_{1}$ investors. Note that Assumption 1 implies that $\pi^{t_{1}}\left(A_{s}\right)>\pi^{t_{2}}\left(A_{s}\right)$ for all $s \leq \hat{s}+1, s \neq 1$ and $\pi^{t_{1}}\left(A_{s}\right)<\pi^{t_{2}}\left(A_{s}\right)$ for all $s>\hat{s}+1$.

Proposition 4. Tranching can be optimal: under Assumption 1, $\sup _{\left(F^{1}, F^{2}\right) \in \mathcal{F}} U^{T}\left(F^{1}, F^{2}\right)>$ $\max \left\{U^{t_{1}}\left(F^{t_{1}}\right), U^{t_{2}}\left(F^{t_{2}}\right)\right\}$.

We prove Proposition 4 by showing that, when Assumption 1 holds, selling an individual security is strictly dominated by selling securities $\left(F^{1}, F^{2}\right) \in \mathcal{F}^{T}$, with $F_{s}^{1}=\min \left\{X_{s,} X_{\hat{s}+1}\right\}$ (i.e., $F^{1}$ is debt with face value $X_{\hat{s}+1}$ ) and

$$
F_{s}^{2}=\left\{\begin{array}{cc}
0 & \text { if } s \leq \hat{s}+1, \\
X_{s}-X_{\hat{s}+1} & \text { if } s \in\left(\hat{s}+1, s_{t_{2}}\right] \\
X_{s_{t_{2}}}-X_{\hat{s}+1} & \text { if } s>s_{t_{2}} .
\end{array}\right.
$$

Security $F^{1}$, which can be thought of as a senior tranche, is bought by investors of type $t_{1}$. Security $F^{2}$, which can be thought of as a junior tranche, is bought by investors of type $t_{2}$. 
Finally, the issuer only retains cash-flows $X_{s}-X_{s_{t_{2}}}$ at states $s>s_{t_{2}} \cdot{ }^{18}$

\section{Convertibles}

This section provides a simple dynamic extension of the disagreement framework. The stylized version of the model presented here introduces the possibility of financing a project in multiple stages and contracts between the issuer (here called an entrepreneur) and investor (the bank or venture capitalist) that can depend on interim performance. We show that convertible securities that are used in venture capital financing naturally arise under the assumption that the issuer and investor's beliefs differ; a key assumption is that the investment project requires a relatively large investment and has high upside potential - i.e., a highly skewed payoff profile. To be able to most clearly illustrate the role of belief differences, we abstract away from many frictions that are relevant for VC contracting, like moral hazard, adverse selection, taxes, etc.

The setup is as follows. The entrepreneur is endowed with an investment opportunity, which requires an initial investment $I_{0}$ at time $t=0$, and offers in period $t=2$ a risky payoff. There are two states of nature, $\{H, L\}$ (high or low). In the interim period, $t=1$, a public and contractible signal is observed, which we specify below. In response to the signal, there are two options for the project:

- the project can be left as is, in which case the returns of the investment at state $s \in\{H, L\}$ are $X_{s}$, with $X_{H}>X_{L}>0$

- the project can be expanded by way of an interim investment $I_{1}>0$, in which case the returns of the investment at state $s \in\{H, L\}$ are $K \times X_{s}$, where $K>1$.

\footnotetext{
${ }^{18}$ The proof of Proposition 4 shows that, under Assumption 1, the solution to the issuer's problem (8) is to solve these two securities.
} 
Let $\pi^{E} \in(0,1)$ and $\pi^{V C} \in(0,1)$ be, respectively, the entrepreneur's and the venture capitalist's initial beliefs that the realized state at $t=2$ will be $H$. We assume that $\pi^{E}>\pi^{V C}$, so the entrepreneur is more optimistic about the project's outcome than the VC.

The interim signal at time $t=1, \sigma$, can take either of two values: $\sigma \in\{h, l\}$. We assume that signals $\sigma=h, l$ are informative about the state of nature: the entrepreneur and the VC believe that

$$
P(\sigma=h \mid s=H)=P(\sigma=l \mid s=L)=\alpha>\frac{1}{2} .
$$

For $\sigma \in\{h, l\}$ and for $i=E, V C$, let $\pi^{i}(\sigma)$ denote the probability that $i$ assigns to the state being $H$ after observing signal $\sigma ; \pi^{i}(l)=\frac{(1-\alpha) \pi^{i}}{(1-\alpha) \pi^{i}+\alpha\left(1-\pi^{i}\right)}<\pi^{i}<\frac{\alpha \pi^{i}}{\alpha \pi^{i}+(1-\alpha)\left(1-\pi^{i}\right)}=\pi^{i}(h)$.

The contract, in exchange for which the entrepreneur receives funding from a competitive VC sector, specifies:

(i) an expansion decision $\mathbf{1}(\sigma) \in\{0,1\}$ to be made at $t=1$ as a function of the signal $\sigma$; $\mathbf{1}(\sigma)=1$ denotes expanding the firm and $\mathbf{1}(\sigma)=0$ denotes not expanding the firm; and

(ii) repayments $z=\left(z_{L}(\sigma), z_{H}(\sigma)\right)$ from the entrepreneur to the VC to be made at $t=2$ : for $s \in\{H, L\}$ and $\sigma \in\{h, l\}, z_{s}(\sigma) \times(1+(K-1) \mathbf{1}(\sigma))$ is the repayment at state $s$ if signal $\sigma$ was observed at the interim stage (with $z_{s}(\sigma) \in\left[0, X_{s}\right]$ ).

We make the following assumptions:

Assumption 2. (i) the $V C$ believes that the project is profitable enough to invest $I_{1}$ at $t=1$ only after observing signal $\sigma=h$ :

$$
(K-1)\left(\pi^{V C}(h) X_{H}+\left(1-\pi^{V C}(h)\right) X_{L}\right)>I_{1}>K\left(\pi^{V C}(l) X_{H}+\left(1-\pi^{V C}(l)\right) X_{L}\right) .
$$


(ii) the $V C$ believes that the project is profitable but risky:

$$
\pi^{V C} X_{H}+\left(1-\pi^{V C}\right) X_{L}>I_{0}>X_{L}
$$

The entrepreneur's expected payoff from contract $(z, \mathbf{1})$ is

$$
\begin{aligned}
U^{E}(z, \mathbf{1}):= & {\left[(1-\alpha) \pi^{E}\left(X_{H}-z_{H}(l)\right)+\alpha\left(1-\pi^{E}\right)\left(X_{L}-z_{L}(l)\right)\right](1+\mathbf{1}(l)(K-1)) } \\
& +\left[\alpha \pi^{E}\left(X_{H}-z_{H}(h)\right)+(1-\alpha)\left(1-\pi^{E}\right)\left(X_{L}-z_{L}(h)\right)\right](1+\mathbf{1}(h)(K-1)(9)
\end{aligned}
$$

The VC's payoff from this contract is

$$
\begin{aligned}
U^{V C}(z, \mathbf{1}):= & {\left[(1-\alpha) \pi^{V C} z_{H}(l)+\alpha\left(1-\pi^{V C}\right) z_{L}(l)\right](1+\mathbf{1}(l)(K-1)) } \\
& +\left[\alpha \pi^{V C} z_{H}(h)+(1-\alpha)\left(1-\pi^{V C}\right) z_{L}(h)\right](1+\mathbf{1}(h)(K-1)) \\
& -\rho_{l} \mathbf{1}(l) I_{1}-\rho_{h} \mathbf{1}(h) I_{1}-I_{0},
\end{aligned}
$$

where $\rho_{l}$ and $\rho_{h}$ denote, respectively, the probability that the $\mathrm{VC}$ assigns to the signal taking values $l$ and $h$, respectively, i.e., $\rho_{l}=(1-\alpha) \pi^{V C}+\alpha\left(1-\pi^{V C}\right)$ and $\rho_{h}=\alpha \pi^{V C}+(1-\alpha)(1-$ $\left.\pi^{V C}\right)$. The problem of the entrepreneur is

$$
\begin{gathered}
\max _{(z, \mathbf{1})} U^{E}(z, \mathbf{1}) \text { s.t. } \\
U^{V C}(z, \mathbf{1}) \geq 0 \\
K\left(\pi^{V C}(\sigma) z_{H}(\sigma)+\left(1-\pi^{V C}(\sigma)\right) z_{L}(\sigma)\right) \geq I_{1} \text { if } \mathbf{1}(\sigma)=1 .
\end{gathered}
$$

Constraint (BE) is the VC's break-even condition. Constraint (EC) requires that, if the VC expands the project at $t=1$, her expected return should cover the investment cost.

Proposition 5. If Assumption 2 holds, the solution to (11) is such that: 
(i) the project is expanded if and only if $\sigma=h$; i.e., $\mathbf{1}(l)=0$ and $\mathbf{1}(h)=1$;

(ii) for $\sigma \in\{l, h\}, z_{L}(\sigma)=X_{L}$;

(iii) $z_{H}(l)$ and $z_{H}(h)$ are such that (BE) holds with equality.

Proposition 5 characterizes the main properties of the solution to (11). Part (i) follows immediately from Assumption 2. Part (ii) follows from the fact that the entrepreneur is relatively more optimistic than the $\mathrm{VC}$, and so the cheapest way to satisfy the VC's breakeven condition is to repay the entire cash-flows at the low state. (This feature is reminiscent of the results in the optimality of debt in Section 3.2.)

Proposition 5 does not pin down what the exact payments at state $H$ are. ${ }^{19}$ However, under further parametric conditions, convertible preferred stock is an optimal contract:

$$
\rho_{H} K X_{L}+\rho_{l} X_{L}<I_{0}+\rho_{h} I_{1}<K\left[(1-\alpha) \pi^{V C} X_{H}+\alpha\left(1-\pi^{V C}\right) X_{L}\right]+\rho_{l} X_{L} .
$$

The first inequality in equation (12) states that the VC does not break even under a contract that specifies repayments $z_{s}(\sigma)=X_{L}$ for $s \in\{L, H\}$ and $\sigma \in\{l, h\}$. The second inequality in equation (12), on the other hand, states that the VC makes a strict profit under a contract that specifies repayments $z_{H}(l)=z_{L}(l)=z_{L}(h)=X_{L}$ and $z_{H}(h)=X_{H}$.

Corollary 6. Suppose Assumption 2 and (12) hold. Then, the following contract solves (11):

(i) the project is expanded if and only if $\sigma=h$; i.e., $\mathbf{1}(l)=0$ and $\mathbf{1}(h)=1$;

(ii) $z_{L}(\sigma)=X_{L}$ for $\sigma \in\{l, h\}$.

(iii) $z_{H}(l)=X_{L}$ and $z_{H}(h) \in\left(X_{L}, X_{H}\right)$ such that (BE) holds with equality.

\footnotetext{
${ }^{19}$ Indeed, given the linearity of the entrepreneur and the VC's payoffs, there is a continuum of optimal contracts. Increasing $z_{H}(l)$ by $\Delta$ allows the entrepreneur to reduce $z_{H}(h)$ by $\frac{1-\alpha}{\alpha} \frac{1}{K} \Delta$ (so that the break even constraint is still satisfied with equality). This change in the contract leaves the entrepreneur indifferent since $-\Delta \pi^{E}(1-\alpha)+\frac{1-\alpha}{\alpha} \frac{1}{K} \Delta \alpha \pi^{E} K=0$.
} 
The optimal contract in Corollary 6 can be implemented by a convertible security that promises $\min \left\{R, K \times X_{L}\right\}$ (where $R$ is the return of the project) to the $\mathrm{VC}$, and gives the VC the following options: (i) after observing interim performance, choose whether or not to invest in expanding the project; and (ii) if the project is expanded, choose whether or not to convert the original security into a fraction $z_{H}(h)$ of equity after observing profits.

The intuition for the result is simple: because the entrepreneur is relatively optimistic about the project's success probability, she finds it relatively valuable to secure the option to expand the project in the future. The VC, on the other hand, finds it relatively cheap to write that option. Of course, $\mathrm{VC}$ and entrepreneur also find it optimal to leave the cash flows to the $\mathrm{VC}$ in case of failure.

\section{Discussion}

The above model illustrates that a disagreement-based theory of security design can explain convertible contracts between entrepreneurs and financiers in a natural way: the entrepreneur's relative optimism is the driving force not only behind the entrepreneur's venture itself, but also behind the financing vehicle that helps her realize the project. Aside from its simplicity, an attractive feature of the model presented here is that highly skewed projects (those with high investment needs and high potential payoffs when everything goes well) receive financing with convertible securities as typically used in VC; optimistic entrepreneurs with less ambitious projects can also finance their ventures with straight debt. ${ }^{20}$

Lastly, while we emphasize the role of disagreement, other frictions including moral hazard, asymmetric information, and taxes are also important for financing young firms and can explain other more intricate features of $\mathrm{VC}$ contracts. Indeed, previous work on $\mathrm{VC}$ financing has highlighted how these frictions shape the types of contracts that a VC will

\footnotetext{
${ }^{20} \mathrm{An}$ additional advantage of convertibles is that they postpone having to a agree on a concrete valuation until a later stage of the project. Because disagreement is reduced by learning, this mechanism gives an additional reason to use convertibles in early-stage financing of relatively optimistic entrepreneurs.
} 
optimally offer to an entrepreneur. For instance, Schmidt (2003) shows how convertibles can be an optimal way of inducing both the entrepreneur and the VC to put costly effort into the project. Bergemann and Hege (1998) show that convertibles can be optimal in a dynamic environment with moral hazard in which both the entrepreneur and the VC need to learn about the feasibility of the project. Finally, convertible securities can be an optimal way of allocating control rights when these rights cannot be separated from cash-flow rights (i.e., Marx (1998)). Our theory complements these studies by highlighting a new force that makes convertibles optimal. Moreover, unlike theories based on control rights, convertible securities are optimal in our theory even when control rights can be separated from cash-flow rights, which is typically the case in real world VC financing (i.e., Kaplan and Strömberg (2003)).

\section{Conclusion}

This paper offers a simple but broadly applicable theory of security design based on the premise that issuer and market openly disagree about the asset's return. In particular, the relative optimism of the issuer about the right tail of the cash-flow distribution determines which security will be issued. As information about the tails, by definition, is scarce, and therefore agreement about the characteristics of the tails is generally unlikely, we think of the theory as widely applicable.

The most frequently issued security - debt - indeed arises as an optimal security in our model. Risk-free debt and equity arise as special cases - the former when there is more disagreement about the right tail, and the latter when the market is more confident about the likelihood of right-tail outcomes and hence there is less disagreement. This feature is strongly consistent with existing empirical results on the dynamics of issuances in general, and the dynamics of the debt-equity mix in issuances in particular. Next, a mild variation in distributional assumptions generates call provisions that are common features of most cor- 
porate debt contracts in the real world but are more difficult to explain with other frictions. Moreover, we find that when the balance sheet is encumbered with pre-existing debt, the firm may cease to issue any security.

We then show that issuing securities backed by a pool of assets (instead of issuing one security for each asset) can be optimal. When there is disagreement among investors, the issuer optimally sells different tranches to the market. These results contribute new testable predictions. In particular, the pooling and tranching results can be used not only to predict the dynamics of securitization, but can potentially also help shed light into the dynamics of corporate events such as mergers and splits, the dynamics of the conglomerate discount, and the issuance of mezzanine tranches.

Finally, in a stylized setting with multiple financing rounds, convertible securities similar to those observed in typical venture capital contracts are optimal to finance high-risk projects with right-skewed payoff profiles. Consistent with empirical realities, the model also predicts that lower-risk projects or projects run by less optimistic entrepreneurs are financed with straight debt.

In sum, we find that disagreement between issuer and market helps explain a variety of real-world security designs that have thus far required multiple distinct models and frictions as explanations. For tractability, our model abstracts away from frictions that are known to be important for security design, such as moral hazard, adverse selection, taxes, etc. Combining disagreement with these frictions may help researchers explain other intricate features of real-world financial contracts that the present study leaves unaddressed. Testing the new empirical predictions arising from our model is also left for future research. 


\section{A Proofs}

\section{Proof of Proposition 1}

Proof. For any security $F \in \mathcal{F}$, the issuer's payoff is

$$
\begin{aligned}
U(F) & =\sum_{s=1}^{K} \pi_{s}^{M} F_{s}+\delta \sum_{s=1}^{K} \pi_{s}^{I}\left(X_{s}-F_{s}\right) \\
& =F_{1}+\sum_{s=2}^{K}\left(\pi^{M}\left(A_{s}\right)-\delta \pi^{I}\left(A_{s}\right)\right)\left(F_{s}-F_{s-1}\right)+\delta \sum_{s=1}^{K} \pi_{s}^{I} X_{s}
\end{aligned}
$$

where the equality follows since, for all distributions $\left(\pi_{s}\right)_{s \in S}$ and all securities $\left(F_{s}\right)_{s \in S}$, $\sum_{s=1}^{K} \pi_{s} F_{s}=F_{1}+\sum_{s=2}^{K} \pi\left(A_{s}\right)\left(F_{s}-F_{s-1}\right)$ (recall that $\left.\pi\left(A_{s}\right)=\sum_{s^{\prime} \geq s} \pi_{s}\right)$. Note that any security $F \in \mathcal{F}$ must be such that $F_{1} \in\left[0, X_{1}\right]$ and for all $s>1, F_{s} \in\left[F_{s-1}, F_{s-1}+X_{s}-X_{s-1}\right]$. Moreover, any security that satisfies these conditions belongs to $\mathcal{F}$. From equation (13), it is optimal to set $F_{1}=X_{1}$. Moreover, for all $s>1$, it is optimal to set $F_{s}=F_{s-1}+X_{s}-X_{s-1}$ if $\pi^{M}\left(A_{s}\right) \geq \delta \pi^{I}\left(A_{s}\right)$, and $F_{s}=F_{s-1}$ if $\pi^{M}\left(A_{s}\right)<\delta \pi^{I}\left(A_{s}\right)$.

\section{Proof of Proposition 2}

Proof. The proof uses arguments similar to those in the proof of Proposition 1. For any security $F \in \mathcal{F}_{D}$, the issuer's payoff is

$$
\begin{aligned}
U(F) & =\sum_{s=1}^{K} \pi_{s}^{M} F_{s}+\delta \sum_{s=1}^{K} \pi_{s}^{I}\left(X_{s}-\min \left\{X_{s}, D\right\}-F_{s}\right) \\
& =F_{1}+\sum_{s=2}^{K}\left(\pi^{M}\left(A_{s}\right)-\delta \pi^{I}\left(A_{s}\right)\right)\left(F_{s}-F_{s-1}\right)+\delta \sum_{s=1}^{K} \pi_{s}^{I}\left(X_{s}-\min \left\{X_{s}, D\right\}\right),
\end{aligned}
$$

Note that any security $F \in \mathcal{F}_{D}$ must be such that $F_{s}=0$ and for all $s \leq s_{D}$, and $F_{s} \in$ $\left[F_{s-1}, F_{s-1}+X_{s}-X_{s-1}\right]$ for all $s>s_{D}$. Moreover, any security that satisfies these conditions 
belongs to $\mathcal{F}_{D}$. Mechanically, any optimal security $F$ must have $F_{s}=0$ and for all $s \leq s_{D}$. From equation (14), for any $s>s_{D}$ it is optimal to set $F_{s}=F_{s-1}+X_{s}-X_{s-1}$ if $\pi^{M}\left(A_{s}\right) \geq$ $\delta \pi^{I}\left(A_{s}\right)$, and to set $F_{s}=F_{s-1}$ if $\pi^{M}\left(A_{s}\right)<\delta \pi^{I}\left(A_{s}\right)$.

\section{Proof of Proposition 3}

Proof. By Corollary 3, under assumption (i) the optimal security backed by a single asset $X^{i}$ is $F^{*}=\min \left\{X_{s}, X_{k}\right\}$. Note that selling two individual securities $F^{*}$, each backed by one of the assets, is the same as selling security $\tilde{F} \in \mathcal{F}_{Y}$ such that

$$
\tilde{F}_{s, s^{\prime}}=\left\{\begin{array}{cc}
X_{s}+X_{s^{\prime}} & \text { if } s, s^{\prime} \leq k, \\
X_{k}+X_{s^{\prime}} & \text { if } s>k, s^{\prime} \leq k, \\
X_{s}+X_{k} & \text { if } s \leq k, s^{\prime}>k, \\
2 X_{k} & \text { if } s>k, s^{\prime}>k .
\end{array}\right.
$$

Consider security the following alternative security $F \in \mathcal{F}_{Y}$

$$
F_{s, s^{\prime}}=\left\{\begin{array}{cc}
X_{s}+X_{s^{\prime}} & \text { if } s, s^{\prime} \leq k, \\
X_{k+1}+X_{s^{\prime}} & \text { if } s>k, s^{\prime} \leq k \\
X_{s}+X_{k+1} & \text { if } s \leq k, s^{\prime}>k, \\
X_{k}+X_{k+1} & \text { if } s>k, s^{\prime}>k
\end{array}\right.
$$

Note that, for any beliefs $\pi$ over $S$,

$$
\begin{aligned}
\sum_{s} \sum_{s^{\prime}} \pi_{s} \pi_{s^{\prime}}\left(F_{s, s^{\prime}}-\tilde{F}_{s, s^{\prime}}\right) & =\sum_{s=1}^{k} \pi_{s}\left(\sum_{s^{\prime}=k+1}^{K} \pi_{s^{\prime}}\left(X_{k+1}-X_{k}\right)\right)+\sum_{s=k+1}^{K} \pi_{s} \sum_{s^{\prime}=1}^{K} \pi_{s^{\prime}}\left(X_{k+1}-X_{k}\right) \\
& =\left(2-\pi\left(A_{k+1}\right)\right) \pi\left(A_{k+1}\right)\left(X_{k+1}-X_{k}\right)
\end{aligned}
$$


Note then that

$$
\begin{aligned}
U_{Y}(F)-2 U\left(F^{*}\right) & =U_{Y}(F)-U_{Y}(\tilde{F}) \\
& =p_{Y}(F)-p_{Y}(\tilde{F})+\delta \sum_{s} \sum_{s^{\prime}} \pi_{s}^{I} \pi_{s^{\prime}}^{I}\left(\tilde{F}_{s, s^{\prime}}-F_{s, s^{\prime}}\right) \\
& =\sum_{s} \sum_{s^{\prime}} \pi_{s}^{M} \pi_{s^{\prime}}^{M}\left(F_{s, s}-\tilde{F}_{s, s^{\prime}}\right)+\delta \sum_{s} \sum_{s^{\prime}} \pi_{s}^{I} \pi_{s^{\prime}}^{I}\left(\tilde{F}_{s, s^{\prime}}-F_{s, s^{\prime}}\right) \\
& =\left(\left(2-\pi^{M}\left(A_{k+1}\right)\right) \pi^{M}\left(A_{k+1}\right)-\delta\left(2-\pi^{I}\left(A_{k+1}\right)\right) \pi^{I}\left(A_{k+1}\right)\right)\left(X_{k+1}-X_{k}\right)>0,
\end{aligned}
$$

where we used equation (15) and condition (ii) in the statement of the Proposition.

\section{Proof of Proposition 4}

Proof. Note that, when solving the issuer's problem, it is without loss of optimality to consider pair of securities $\left(F^{1}, F^{2}\right) \in \mathcal{F}^{T}$ with the property that $F^{1}$ is bought by investors of type $t_{1}$ and $F^{2}$ is bought by investors of type $t_{2}$. This is indeed without loss if the two securities $\left(F^{1}, F^{2}\right)$ are bought by different types of investors. If the two securities $\left(F^{1}, F^{2}\right)$ are bought by investors of type $t_{i}$, then the issuer's payoff from selling security $\left(F^{1}, F^{2}\right)$ is

$$
U^{T}\left(F^{1}, F^{2}\right)=\sum_{s \in S} \pi^{t_{i}}\left(F_{s}^{1}+F_{S}^{2}\right)+\delta \sum_{s \in S} \pi_{s}^{I}\left(X_{s}-F_{s}^{1}-F_{s}^{2}\right)
$$

Consider the pair of securities $\left(\tilde{F}^{1}, \tilde{F}^{2}\right)$ with $\tilde{F}_{s}^{i}=F_{s}^{1}+F_{s}^{2}$ for all $s$ and $\tilde{F}_{s}^{j}=0$ for all $s$, and note that

$$
U^{T}\left(\tilde{F}^{1}, \tilde{F}^{2}\right)=\sum_{s \in S} \pi_{s}^{t_{i}}\left(F_{s}^{1}+F_{S}^{2}\right)+\delta \sum_{s \in S} \pi_{s}^{I}\left(X_{s}-F_{s}^{1}-F_{s}^{2}\right)=U^{T}\left(F^{1}, F^{2}\right)
$$

Moreover, when the issuer sells securities $\left(\tilde{F}^{1}, \tilde{F}^{2}\right)$, investors of type $t_{i}$ buy security $\tilde{F}^{i}$ and investors of type $t_{j}$ (trivially) buy security $\tilde{F}^{j}$. Hence, when solving the issuer's problem, it 
is without loss of optimality to consider pair of securities $\left(F^{1}, F^{2}\right) \in \mathcal{F}^{T}$ with the property that $F^{1}$ is bought by investors of type $t_{1}$ and $F^{2}$ is bought by investors of type $t_{2}$.

Fix a pair of securities $\left(F^{1}, F^{2}\right) \in \mathcal{F}^{T}$ such that, for $i=1,2$, security $F^{i}$ is bought by investors of type $t_{i}$. The issuer's payoff from selling this pair of securities is

$$
\begin{aligned}
U^{T}\left(F^{1}, F^{2}\right) & =\sum_{s=1}^{K} \pi_{s}^{t_{1}} F_{s}^{1}+\sum_{s=1}^{K} \pi_{s}^{t_{2}} F_{s}^{2}+\delta \sum_{s=1}^{K} \pi_{s}^{I}\left(X_{s}-F_{s}^{1}-F_{s}^{2}\right) \\
& =F_{1}^{1}+F_{1}^{2}+\sum_{s=2}^{K}\left(\pi^{t_{1}}\left(A_{s}\right)-\delta \pi^{I}\left(A_{s}\right)\right) F_{s}^{1}+\sum_{s=2}^{K}\left(\pi^{t_{2}}\left(A_{s}\right)-\delta \pi^{I}\left(A_{s}\right)\right) F_{s}^{2}+\delta \sum_{s=1}^{K} \pi_{s}^{I} X_{s} .
\end{aligned}
$$

Note that any pair of securities $\left(F^{1}, F^{2}\right) \in \mathcal{F}^{T}$ must be such that: (i) $F_{1}^{1}+F_{1}^{2} \in\left[0, X_{1}\right]$, (ii) for all $s>1, F_{s}^{1}+F_{s}^{2} \in\left[F_{s-1}^{1}+F_{s-1}^{2}, F_{s-1}^{1}+F_{s-1}^{2}+X_{s}-X_{s-1}\right]$ and (iii) for $i=1,2, F_{s}^{i} \geq F_{s-1}^{i}$. Note further that, from equation (16), it is optimal for the issuer to set $F_{1}^{1}+F_{1}^{2}=X_{1}$, and for $s>1, i=1,2, F_{s}^{i}=F_{s-1}^{1}+F_{s-1}^{2}+X_{s}-X_{s-1}$ if $\pi^{t_{i}}\left(A_{s}\right) \geq \delta \pi^{I}\left(A_{s}\right)$ and $\pi^{t_{i}}\left(A_{s}\right)>\pi^{t_{j}}\left(A_{s}\right)$, and to set $F_{s}^{i}=F_{s-1}^{i}$ otherwise.

Suppose next that Assumption (1) holds. Let $\left(F^{1}, F^{2}\right) \in \mathcal{F}^{T}$ be such that $F_{s}^{1}=\min \left\{X_{s}, X_{\hat{s}+1}\right\}$ and

$$
F_{s}^{2}=\left\{\begin{array}{cc}
0 & \text { if } s \leq \hat{s}+1, \\
X_{s}-X_{\hat{s}+1} & \text { if } s \in\left(\hat{s}+1, s_{t_{2}}\right], \\
X_{s_{t_{2}}}-X_{\hat{s}+1} & \text { if } s>s_{t_{2}} .
\end{array}\right.
$$

Under Assumption (1), securities $\left(F^{1}, F^{2}\right)$ satisfy the maximizing conditions in the previous paragraph: i.e., $F_{1}^{1}+F_{1}^{2}=X_{1}$, and for $s>1, i=1,2, F_{s}^{i}=F_{s-1}^{1}+F_{s-1}^{2}+X_{s}-X_{s-1}$ if $\pi^{t_{i}}\left(A_{s}\right) \geq \delta \pi^{I}\left(A_{s}\right)$ and $\pi^{t_{i}}\left(A_{s}\right)>\pi^{t_{j}}\left(A_{s}\right)$, and to set $F_{s}^{i}=F_{s-1}^{i}$ otherwise.

We now complete the proof of the proposition by showing that $U^{T}\left(F^{1}, F^{2}\right)>\max \left\{U^{t_{1}}\left(F^{t_{1}}\right), U^{t_{2}}\left(F^{t_{2}}\right)\right\}$. 
Note first that for any security $F$ and for any beliefs $\pi$,

$$
\sum_{s} \pi_{s} F_{s}=F_{1}+\sum_{s \geq 2} \pi\left(A_{s}\right)\left(F_{s}-F_{s-1}\right)
$$

By equation (17), for $\tau=t_{1}, t_{2}$,

$$
p^{\tau}\left(F^{1}\right)=\sum_{s} \pi_{s}^{\tau} F_{s}^{1}=X_{1}+\sum_{s \in[2, \hat{s}+1]} \pi^{\tau}\left(A_{s}\right)\left(X_{s}-X_{s-1}\right)
$$

Assumption 1 implies that $p^{t_{1}}\left(F^{1}\right)>p^{t_{2}}\left(F^{1}\right)$; i.e., $t_{1}$-investors are willing to pay more for security $F^{1}$ than $t_{2}$-investors. Similarly, using again equation (17), for $\tau=t_{1}, t_{2}$,

$$
p^{\tau}\left(F^{2}\right)=\sum_{s} \pi_{s}^{\tau} F_{s}^{2}=\sum_{s \in\left[\hat{s}+2, s_{t_{2}}\right]} \pi^{\tau}\left(A_{s}\right)\left(X_{s}-X_{s-1}\right) .
$$

Assumption 1 implies that $p^{t_{2}}\left(F^{2}\right)>p^{t_{1}}\left(F^{2}\right)$; i.e., $t_{2}$-investors are willing to pay more for security $F^{2}$ than $t_{1}$-investors. Therefore,

$$
\begin{aligned}
U^{T}\left(F^{1}, F^{2}\right)= & p^{t_{1}}\left(F^{1}\right)+p^{t_{2}}\left(F^{2}\right)+\delta \sum_{s} \pi_{s}^{I}\left(X_{s}-F_{s}^{1}-F_{s}^{2}\right) \\
= & X_{1}+\sum_{s \in[2, \hat{s}+1]} \pi^{t_{1}}\left(A_{s}\right)\left(X_{s}-X_{s-1}\right)+\sum_{s \in\left[\hat{s}+2, s_{t_{2}}\right]} \pi^{t_{2}}\left(A_{s}\right)\left(X_{s}-X_{s-1}\right) \\
& +\delta \sum_{s \in\left[s_{t_{2}}+1, K\right]} \pi^{I}\left(A_{s}\right)\left(X_{s}-X_{s-1}\right),
\end{aligned}
$$

where the second equality in (18) follows since, by equation (17), $\sum_{s} \pi_{s}^{I}\left(X_{s}-F_{s}^{1}-F_{s}^{2}\right)=$ $\sum_{s \in\left[s_{t_{2}}+1, K\right]} \pi^{I}\left(A_{s}\right)\left(X_{s}-X_{s-1}\right)$.

On the other hand, the issuer's highest payoff from selling a single security is $\max \left\{U^{t_{1}}\left(F^{t_{1}}\right), U^{t_{2}}\left(F^{t_{2}}\right)\right\}$. 
Since $F_{s}^{\tau}=\min \left\{X_{s}, X_{s_{\tau}}\right\}$,

$$
\begin{aligned}
U^{\tau}\left(F^{\tau}\right) & =p^{\tau}\left(F^{\tau}\right)+\delta \sum_{s>s_{\tau}} \pi_{s}^{I}\left(X_{s}-X_{s_{\tau}}\right) \\
& =X_{1}+\sum_{s \in\left[2, s_{\tau}\right]} \pi^{\tau}\left(A_{s}\right)\left(X_{s}-X_{s-1}\right)+\delta \sum_{s \in\left[s_{\tau}+1, K\right]} \pi^{I}\left(A_{s}\right)\left(X_{s}-X_{s-1}\right) .
\end{aligned}
$$

Using (18) and (19):

$$
\begin{aligned}
U^{T}\left(F^{1}, F^{2}\right)-U^{t_{1}}\left(F^{t_{1}}\right)= & \sum_{s \in\left[\hat{s}+2, s_{t_{2}}\right]} \pi^{t_{2}}\left(A_{s}\right)\left(X_{s}-X_{s-1}\right)+\delta \sum_{s \in\left[s_{t_{2}}+1, K\right]} \pi^{I}\left(A_{s}\right)\left(X_{s}-X_{s-1}\right) \\
& -\sum_{s \in\left[\hat{s}+2, s_{t_{1}}\right]} \pi^{t_{1}}\left(A_{s}\right)\left(X_{s}-X_{s-1}\right)-\delta \sum_{s \in\left[s_{t_{1}}+1, K\right]} \pi^{I}\left(A_{s}\right)\left(X_{s}-X_{s-1}\right) \\
= & \sum_{s \in\left[\hat{s}+2, s_{t_{1}}\right]}\left(\pi^{t_{2}}\left(A_{s}\right)-\pi^{t_{1}}\left(A_{s}\right)\right)\left(X_{s}-X_{s-1}\right) \\
& +\sum_{s \in\left[s_{t_{1}}+1, s_{t_{2}}\right]}\left(\pi^{t_{2}}\left(A_{s}\right)-\delta \pi^{I}\left(A_{s}\right)\right)\left(X_{s}-X_{s-1}\right)>0,
\end{aligned}
$$

where the inequality follows since $\pi^{t_{2}}\left(A_{s}\right)>\pi^{t_{1}}\left(A_{s}\right)$ for all $s \in\left[\hat{s}+2, s_{t_{1}}\right]$ (Assumption (1)) and since $\pi^{t_{2}}\left(A_{s}\right) \geq \delta \pi^{I}\left(A_{s}\right)$ for all $s \leq s_{t_{2}}$. Similarly,

$$
U^{T}\left(F^{1}, F^{2}\right)-U^{t_{2}}\left(F^{t_{2}}\right)=\sum_{s \in[2, \hat{s}+1]}\left(\pi^{t_{1}}\left(A_{s}\right)-\pi^{t_{2}}\left(A_{2}\right)\right)\left(X_{s}-X_{s-1}\right)>0,
$$

where the strict inequality follows since $\pi^{t_{2}}\left(A_{s}\right)<\pi^{t_{1}}\left(A_{s}\right)$ for all $s \in[2, \hat{s}]$ (Assumption (1)). Therefore, $U^{T}\left(F^{1}, F^{2}\right)>\max \left\{U^{t_{1}}\left(F^{t_{1}}\right), U^{t_{2}}\left(F^{t_{2}}\right)\right\}$.

\section{Proofs of Proposition 5 and Corollary 6}

Before presenting the proofs of Proposition 5 and Corollary 6, we establish two useful lemmas.

Lemma 1. Let $(z, \mathbf{1})$ be a solution to (11). If $z_{H}(\sigma)>0$ for $\sigma \in\{l, h\}$, then it must be that 
$z_{L}(\sigma)=X_{L}$

Proof. Suppose by contradiction that $z_{H}(\sigma)>0$ and $z_{L}(\sigma)<X_{L}$ for $\sigma \in\{l, h\}$. Suppose first that $\sigma=h$, and consider a contract $(\tilde{z}, \mathbf{1})$ such that $\tilde{z}_{s}(l)=z_{s}(l)$ for $s=H, L, \tilde{z}_{L}(h)=$ $z_{L}(h)+\epsilon$ and $\tilde{z}_{H}(h)=z_{H}(h)-\frac{1-\alpha}{\alpha} \frac{1-\pi^{V C}}{\pi^{V C}} \epsilon$, with $\epsilon>0$. Note that contract $(\tilde{z}, 1)$ gives the $\mathrm{VC}$ the same expected payoff as contract $(z, \mathbf{1})$. Note further that

$$
\begin{aligned}
U^{E}(\tilde{z}, \mathbf{1})-U^{E}(z, \mathbf{1}) & =(1+\mathbf{1}(h)(K-1))\left(\alpha \pi^{E} \frac{1-\alpha}{\alpha} \frac{1-\pi^{V C}}{\pi^{V C}} \epsilon-(1-\alpha)\left(1-\pi^{E}\right) \epsilon\right) \\
& =(1+\mathbf{1}(h)(K-1)) \frac{(1-\alpha) \epsilon}{\pi^{V C}}\left(\pi^{E}\left(1-\pi^{V C}\right)-\pi^{V C}\left(1-\pi^{E}\right)\right)>0,
\end{aligned}
$$

where we used $\pi^{E}>\pi^{V C}$. This contradicts the assumption that $(z, \mathbf{1})$ is optimal.

Suppose next that $\sigma=l$. Consider a contract $(\tilde{z}, \mathbf{1})$ such that $\tilde{z}_{s}(h)=z_{s}(h)$ for $s=H, L$, $\tilde{z}_{L}(l)=z_{L}(l)+\epsilon$ and $\tilde{z}_{H}(l)=z_{H}(l)-\frac{\alpha}{1-\alpha} \frac{1-\pi^{V C}}{\pi^{V C}} \epsilon$, with $\epsilon>0$. Note that $\operatorname{contract}(\tilde{z}, 1)$ gives the $\mathrm{VC}$ the same expected payoff as contract $(z, \mathbf{1})$, and

$$
\begin{aligned}
U^{E}(\tilde{z}, \mathbf{1})-U^{E}(z, \mathbf{1}) & =(1+\mathbf{1}(l)(K-1))\left((1-\alpha) \pi^{E} \frac{\alpha}{1-\alpha} \frac{1-\pi^{V C}}{\pi^{V C}} \epsilon-\alpha\left(1-\pi^{E}\right) \epsilon\right) \\
& =(1+\mathbf{1}(l)(K-1)) \frac{\alpha \epsilon}{\pi^{V C}}\left(\pi^{E}\left(1-\pi^{V C}\right)-\pi^{V C}\left(1-\pi^{E}\right)\right)>0 .
\end{aligned}
$$

Again this contradicts the assumption that $(z, \mathbf{1})$ is optimal.

Lemma 2. Let $(z, \mathbf{1})$ be a solution to (11). Under Assumption $2, z_{L}(\sigma)=X_{L}$ for $\sigma \in\{l, h\}$.

Proof. Let $(z, \mathbf{1})$ be a solution to (11). The conditions in Assumption 2 imply that, in order for the VC to break even, it must be that $z_{H}(h)>0$ and/or $z_{H}(l)>0$. If both of these quantities are strictly positive, then the result follows from Lemma 1.

Suppose next that $z_{H}(h)=0$ and $z_{H}(l)>0$. By Lemma $1, z_{L}(l)=X_{L}$. Towards a contradiction, suppose $z_{L}(h)<X_{L}$. Let $(\hat{z}, \mathbf{1})$ be an alternative contract with $\hat{z}_{L}(\sigma)=z_{L}(\sigma)$ for $\sigma=h, l, \hat{z}_{H}(l)=z_{H}(l)-\epsilon$ and $\hat{z}_{H}(l)=z_{H}(h)+\frac{1-\alpha}{\alpha} \frac{1+\mathbf{1}(l)(K-1)}{1+\mathbf{1}(h)(K-1)} \epsilon$, with $\epsilon>0$. Contract 
$(\hat{z}, \mathbf{1})$ gives entrepreneur and $\mathrm{VC}$ the same expected payoff as contract $(z, \mathbf{1})$, so it is also an optimal contract. But this contradicts Lemma 1, since $\hat{z}_{L}(h)=z_{L}(h)<X_{L}$ and $\hat{z}_{H}(h)>0$. Hence, if $(z, \mathbf{1})$ is an optimal contract with $z_{H}(h)=0$ and $z_{H}(l)>0$, it must that $z_{L}(\sigma)=X_{L}$ for $\sigma \in\{l, h\}$.

Finally, consider the case with $z_{H}(h)>0$ and $z_{H}(l)=0$. By Lemma $1, z_{L}(h)=X_{L}$. Towards a contradiction, suppose $z_{L}(l)<X_{L}$. Let $(\hat{z}, \mathbf{1})$ be an alternative contract with $\hat{z}_{L}(\sigma)=z_{L}(\sigma)$ for $\sigma=h, l, \hat{z}_{H}(l)=z_{H}(l)+\epsilon$ and $\hat{z}_{H}(l)=z_{H}(h)-\frac{1-\alpha}{\alpha} \frac{1+\mathbf{1}(l)(K-1)}{1+\mathbf{1}(h)(K-1)} \epsilon$. Again, contract $(\hat{z}, \mathbf{1})$ gives entrepreneur and VC the same expected payoff as contract $(z, \mathbf{1})$, so it is also an optimal contract. But this contradicts Lemma 1, since $\hat{z}_{L}(l)=z_{L}(l)<X_{L}$ and $\hat{z}_{H}(l)>0$. Hence, if $(z, \mathbf{1})$ is an optimal contract with $z_{H}(h)>0$ and $z_{H}(l)=0$, it must be that $z_{L}(\sigma)=X_{L}$ for $\sigma \in\{l, h\}$.

Proof of Proposition 5. Part (ii) follows from Lemma 2.

We now prove part (i). Note first that, under Assumption 2, any optimal contract $(z, \mathbf{1})$ must be such that $\mathbf{1}(l)=0$ : indeed, under the condition (i) in Assumption 2, there are no feasible repayments $z$ that satisfy constraint (EC) for $\sigma=l$ when $\mathbf{1}(l)=1$.

We now show that, under an optimal contract, $\mathbf{1}(h)=1$. Suppose that there exists an optimal contract $(z, \mathbf{1})$ with $\mathbf{1}(h)=0$. Let $(\tilde{z}, \tilde{\mathbf{1}})$ be an alternative contract with $\tilde{\mathbf{1}}(h)=1$, $\tilde{\mathbf{1}}(l)=\mathbf{1}(l)=0, \tilde{z}_{L}(\sigma)=z_{L}(\sigma)=X_{L}, \tilde{z}_{H}(l)=z_{H}(l)$ and

$$
\begin{aligned}
\tilde{z}_{H}(h) & =\frac{\rho_{h} I_{1}+\alpha \pi^{V C} z_{H}(h)+(1-\alpha)\left(1-\pi^{V C}\right) z_{L}(h)}{K \alpha \pi^{V C}}-\frac{1-\alpha}{\alpha} \frac{1-\pi^{V C}}{\pi^{V C}} z_{L}(h) \\
& =\frac{\rho_{h} I_{1}+\alpha \pi^{V C} z_{H}(h)+(1-\alpha)\left(1-\pi^{V C}\right) X_{L}}{K \alpha \pi^{V C}}-\frac{1-\alpha}{\alpha} \frac{1-\pi^{V C}}{\pi^{V C}} X_{L},
\end{aligned}
$$

where the second equality follows since, under any optimal contract, $z_{L}(h)=X_{L}$. Note that the VC's expected payoff under contract $(\tilde{z}, \tilde{\mathbf{1}})$ is the same as her expected payoff under 
contract $(z, \mathbf{1})$. Note further that

$$
\begin{aligned}
U^{E}(\tilde{z}, \tilde{\mathbf{1}})-U^{E}(z, \mathbf{1}) & =K \alpha \pi^{E}\left(X_{H}-\tilde{z}_{H}(h)\right)-\alpha \pi^{E}\left(X_{H}-z_{H}(h)\right) \\
& =\alpha \pi^{E}\left[(K-1) X_{H}+(K-1) \frac{1-\alpha}{\alpha} \frac{1-\pi^{V C}}{\pi^{V C}} X_{L}-\frac{\rho_{h} I_{1}}{\alpha \pi^{V C}}\right] \\
& =\frac{\pi^{E}}{\pi^{V C}}\left[(K-1) \alpha \pi^{V C} X_{H}+(K-1)(1-\alpha)\left(1-\pi^{V C}\right) X_{L}-\rho_{h} I_{1}\right]>0,
\end{aligned}
$$

where the strict inequality follows from Assumption 2. Hence, if $(z, \mathbf{1})$ is an optimal contract it must have $\mathbf{1}(h)=1$. This establishes part (i).

Finally, part (iii) follows since any optimal contract $(z, \mathbf{1})$ must be such that $U^{V C}(z, \mathbf{1})=$ 0 . Further, we note that if there exists an optimal contract $(z, \mathbf{1})$ such that $U^{V C}(z, \mathbf{1})=0$ and such that (EC) is satisfied with slack, then there exists a continuum of optimal contracts. Indeed, increasing $z_{H}(l)$ by $\epsilon$ allows the entrepreneur to reduce $z_{H}(h)$ by $\frac{1-\alpha}{\alpha} \frac{1}{K} \epsilon$ while still satisfying the VC's break even condition. This change in the contract leaves the entrepreneur indifferent since $-\epsilon \pi^{E}(1-\alpha)+\frac{1-\alpha}{\alpha} \frac{1}{K} \epsilon \alpha \pi^{E} K=0$.

Proof of Corollary 6. Parts (i) and (ii) follow from Proposition (5). Finally, when the first inequality in (12) holds, the VC must get strictly more than $X_{L}$ at state $s=H$ when $\sigma=l$ and/or $\sigma=h$ (otherwise the $\mathrm{VC}$ does not break even). When the second inequality in (12) holds, there exists $z \in\left(X_{L}, X_{H}\right)$ such that

$$
I_{0}+\rho_{h} I_{1}=K\left[(1-\alpha) \pi^{V C} z+\alpha\left(1-\pi^{V C}\right) X_{L}\right]+\rho_{l} X_{L}
$$

By equation (20), the $\mathrm{VC}$ breaks even under a contract $(z, \mathbf{1})$ with $\mathbf{1}(h)=1, \mathbf{1}(l)=0$, $z_{L}(l)=z_{L}(h)=z_{H}(l)=X_{L}$ and $z_{H}(h)=z$. Finally, since $I_{0}>\rho_{L} X_{L}$ (by Assumption (2)), 
equation (20) implies that

$$
K\left[(1-\alpha) \pi^{V C} z+\alpha\left(1-\pi^{V C}\right) X_{L}\right]>\rho_{H} I_{1},
$$

so that (EC) holds. Hence, by Proposition (5), contract $(z, \mathbf{1})$ is optimal.

\section{B Generalization to Non-monotonic Securities}

Throughout section 3.2 we restricted the issuer to sell monotonic securities. For completeness, we now briefly describe how our results are modified if we drop this restriction. Let

$$
\mathcal{F}^{u}:=\left\{F \in \mathbb{R}^{K}: 0 \leq F_{s} \leq X_{s}\right\}
$$

be the unrestricted set of securities backed by asset $X$. Without the restriction to monotonic securities, the issuer's problem is

$$
\sup _{F \in \mathcal{F}^{u}} U(F) .
$$

The following result characterizes the optimal security when we relax the restriction to monotonic securities.

Proposition 6. The solution to (21) is described by:

$$
\forall s \in S, \quad F_{s}= \begin{cases}X_{s} & \text { if } \pi_{s}^{M}>\delta \pi_{s}^{I}, \\ a \in\left[0, X_{s}\right] & \text { if } \pi_{s}^{M}=\delta \pi_{s}^{I}, \\ 0 & \text { if } \pi_{s}^{M}<\delta \pi_{s}^{I} .\end{cases}
$$

Proof. For any $s \in S$, the payoff that the issuer gets from selling cash-flows $F_{s} \in\left[0, X_{s}\right]$ 
at state $s$ is $\pi_{s}^{M} F_{s}$, while the payoff she gets from retaining those cash-flows is $\delta \pi_{s}^{I} F_{s}$. It is optimal for the issuer to set $F_{s}=X_{s}$ if $\pi_{s}^{M}>\delta \pi_{s}^{I}$, and to set $F_{s}=0$ if $\pi_{s}^{M}<\delta \pi_{s}^{I}$. Finally, the issuer is indifferent between setting $F_{s}=a \in\left[0, X_{s}\right]$ if $\pi_{s}^{M}=\delta \pi_{s}^{I}$.

To gain intuition about the shape of the security that solves (21), suppose $\frac{\pi_{s}^{I}}{\pi_{s}^{M}}$ is increasing in $s$ and let $k=\max \left\{s: \frac{\pi_{s}^{M}}{\pi_{s}^{I}} \geq \delta\right\}$. Then, by Proposition 6, the security that solves (21) is

$$
\forall s \in S, \quad F_{s}= \begin{cases}X_{s} & \text { if } s \leq k \\ 0 & \text { if } s>k\end{cases}
$$

Hence, the restriction to monotonic securities serves the same purpose as in the existing literature: indeed, without this restriction, the same security obtains as in a standard asymmetric information or moral hazard framework, see, e.g., Innes (1990). Finally, Simsek (2013a) derives the same security in a setting with disagreement among investors.

\section{Generalization of the Simple Pooling Example}

This appendix extends the example of section 4.1 to allow for non-zero correlation between the assets to be securitized. As in section 4.1, suppose the issuer owns two assets, $X^{1}$ and $X^{2}$, each of which can generate a return in $\left\{X_{1}, X_{2}\right\}$ (with $X_{1}<X_{2}$ ). In contrast to section 4.1, suppose that the returns of assets $X^{1}$ and $X^{2}$ are correlated. Let $s k \in \hat{S}=\{11,12,21,22\}$ denote the event that asset 1's return is $X_{s}$ and asset 2's return is $X_{k}$. The beliefs of the issuer and market over the set of possible return realizations are, respectively, $\hat{\pi}^{I}$ and $\hat{\pi}^{M}$. For $j=I, M, \hat{\pi}_{s k}^{j}$ denotes the probability that $j$ assigns to the event $s k$. We assume that the assets are symmetric, so that $\hat{\pi}_{12}^{j}=\hat{\pi}_{21}^{j}$ for $j=I, M$. The iid case of section 4.1 is the special case with $\hat{\pi}_{s k}^{j}=\pi_{s}^{j} \pi_{k}^{j}$ for $j=I, M$ and for all $s k \in \hat{S}$.

Suppose first that the issuer sells two individual securities, each backed by an asset. By 
Proposition 1 an optimal security $F$ has $F_{1}=X_{1}$ and $F_{2} \geq F_{1}$. The price that the market is willing to pay for security $F$ is $p(F)=X_{1}\left(\hat{\pi}_{11}^{M}+\hat{\pi}_{12}^{M}\right)+F_{2}\left(\hat{\pi}_{21}^{M}+\hat{\pi}_{22}^{M}\right)$; the issuer's payoff from selling this security is

$$
p(F)+\delta\left(X_{2}-F_{2}\right)\left(\hat{\pi}_{21}^{M}+\hat{\pi}_{22}^{M}\right)=X_{1}\left(\hat{\pi}_{11}^{M}+\hat{\pi}_{12}^{M}\right)+F_{2}\left(\hat{\pi}_{21}^{M}+\hat{\pi}_{22}^{M}\right)+\delta\left(X_{2}-F_{2}\right)\left(\hat{\pi}_{21}^{I}+\hat{\pi}_{22}^{I}\right) .
$$

The issuer finds it optimal to set $F_{2}=X_{1}$ if $\delta\left(\hat{\pi}_{21}^{I}+\hat{\pi}_{22}^{I}\right)>\hat{\pi}_{21}^{M}+\hat{\pi}_{22}^{M}$ and $F_{2}=X_{2}$ if $\delta\left(\hat{\pi}_{21}^{I}+\hat{\pi}_{22}^{I}\right) \leq \hat{\pi}_{21}^{M}+\hat{\pi}_{22}^{M}$. In what follows we maintain the assumption that $\delta\left(\hat{\pi}_{21}^{I}+\hat{\pi}_{22}^{I}\right)>$ $\hat{\pi}_{21}^{M}+\hat{\pi}_{22}^{M}$, so that an issuer who sells individual securities $F^{1}$ and $F^{2}$, each backed respectively by asset $X^{1}$ and $X^{2}$, finds it optimal to set $F_{s}^{1}=F_{s}^{2}=X_{1}$ for $s=1,2$.

Suppose next that the issuer pools the two assets and sells a single security backed by cash-flows $Y=X^{1}+X^{2}$. Consider a security $F_{Y}=\min \left\{Y, X_{1}+X_{2}\right\}$. The price that the market is willing to pay for security $F_{Y}$ is $p\left(F_{Y}\right)=\hat{\pi}_{11}^{M} 2 X_{1}+\left(1-\hat{\pi}_{11}^{M}\right)\left(X_{1}+X_{2}\right)$, and the issuer's payoff from selling this security is

$$
p\left(F_{Y}\right)+\delta \hat{\pi}_{22}^{I}\left(X_{2}-X_{1}\right)=\hat{\pi}_{11}^{M} 2 X_{1}+\left(1-\hat{\pi}_{11}^{M}\right)\left(X_{1}+X_{2}\right)+\delta \hat{\pi}_{22}^{I}\left(X_{2}-X_{1}\right) .
$$

Comparing (22) and (23), the issuer strictly prefers selling security $F_{Y}$ backed by the pool of assets than selling the two individual securities $F_{s}^{1}=F_{s}^{2}=X_{1}$ for $s=1,2$ if and only if $2 \hat{\pi}_{21}^{M}+\hat{\pi}_{22}^{M}=1-\hat{\pi}_{11}^{M}>\delta\left(1-\pi_{11}^{I}\right)=\delta\left(2 \hat{\pi}_{21}^{I}+\hat{\pi}_{22}^{I}\right)$. Combining this with $\delta\left(\hat{\pi}_{21}^{I}+\hat{\pi}_{22}^{I}\right)>\hat{\pi}_{21}^{M}+\hat{\pi}_{22}^{M}$, the issuer strictly prefers to pool the assets and sell security $F_{Y}$ if

$$
\hat{\pi}_{11}^{M} \in\left(1-\delta\left(\hat{\pi}_{21}^{I}+\hat{\pi}_{22}^{I}\right)-\hat{\pi}_{21}^{M}, 1-\delta\left(2 \hat{\pi}_{21}^{I}+\hat{\pi}_{22}^{I}\right)\right) .
$$

If the issuer and the market both perceive the asset to be perfectly correlated (so that $\hat{\pi}_{21}^{j}=0$ for $j=1,2$ ), the condition in (24) can never be satisfied, and hence pooling does not obtain. 


\section{References}

Adam, Tim R., Valentin Burg, Tobias Scheinert, and Daniel Streitz, "Managerial Optimism and Debt Contract Design: The Case of Syndicated Loans," Working Paper, 2014 .

Admati, Anat R. and Paul Pfleiderer, "Robust Financial Contracting and the Role of Venture Capitalists," The Journal of Finance, 1994, 49 (2), 371-402.

Adrian, Tobias and Mark M Westerfield, "Disagreement and learning in a dynamic contracting model," Review of Financial Studies, 2009, 22 (10), 3873-3906.

Allen, Franklin and Douglas Gale, "Optimal security design," Review of Financial Studies, 1988, 1 (3), 229-263.

Antic, Nemanja, "Contracting with unknown technologies," Working Paper, 2014.

Arora, Sanjeev, Boaz Barak, Markus Brunnermeier, and Rong Ge, "Computational complexity and information asymmetry in financial products," Technical Report, Princeton University Working Paper 2013.

Axelson, Ulf, "Security design with investor private information," The Journal of Finance, 2007, 62 (6), 2587-2632.

Baker, Malcolm and Jeffrey Wurgler, "Market timing and capital structure," The Journal of Finance, 2002, 57 (1), 1-32.

Bayar, Onur, Thomas J Chemmanur, and Mark H Liu, "A theory of equity carve-outs and negative stub values under heterogeneous beliefs," Journal of Financial Economics, 2011, $100(3), 616-638$. 
$\ldots, \ldots$, and _ , "A theory of capital structure, price impact, and long-run stock returns under heterogeneous beliefs," Journal of Corporate Finance Studies, forthcoming.

Bergemann, Dirk and Ulrich Hege, "Venture capital financing, moral hazard, and learning," Journal of Banking $\mathcal{E}$ Finance, 1998, 22 (6), 703-735.

Bergman, Nittai K and Dirk Jenter, "Employee sentiment and stock option compensation," Journal of Financial Economics, 2007, 84 (3), 667-712.

Bernardo, Antonio E and Ivo Welch, "On the evolution of overconfidence and entrepreneurs," Journal of Economics \&3 Management Strategy, 2001, 10 (3), 301-330.

Boot, Arnoud WA and Anjan V Thakor, "Managerial autonomy, allocation of control rights, and optimal capital structure," Review of Financial Studies, 2011, pp. 3434-3485.

_, Radhakrishnan Gopalan, and Anjan V Thakor, "The entrepreneur's choice between private and public ownership," The Journal of Finance, 2006, 61 (2), 803-836.

_ , _ , and _ , "Market liquidity, investor participation, and managerial autonomy: why do firms go private?," The Journal of Finance, 2008, 63 (4), 2013-2059.

Börgers, Tilman, "(No) Foundations of Dominant-Strategy Mechanisms: A Comment on Chung and Ely (2007)," Working Paper, 2014.

Brunnermeier, Markus K, Alp Simsek, and Wei Xiong, "A welfare criterion for models with distorted beliefs," Quarterly Journal of Economics, forthcoming.

Chernenko, Sergey, Sam Hanson, and Adi Sunderam, "The Rise and Fall of Securitization," Technical Report, Working Paper, December 2013.

Cochrane, John H, "The risk and return of venture capital," Journal of Financial Economics, 2005, 75 (1), 3-52. 
Cooper, Arnold C, Carolyn Y Woo, and William C Dunkelberg, "Entrepreneurs' perceived chances for success," Journal of Business Venturing, 1988, 3 (2), 97-108.

Cornelli, Francesca and Oved Yosha, "Stage financing and the role of convertible securities," The Review of Economic Studies, 2003, 70 (1), 1-32.

Coval, Joshua D and Anjan V Thakor, "Financial intermediation as a beliefs-bridge between optimists and pessimists," Journal of Financial Economics, 2005, 75 (3), 535-569.

DeMarzo, Peter and Darrell Duffie, "A liquidity-based model of security design," Econometrica, 1999, 67 (1), 65-99.

DeMarzo, Peter M, "The pooling and tranching of securities: A model of informed intermediation," Review of Financial Studies, 2005, 18 (1), 1-35.

Dicks, David and Paolo Fulghieri, "Ambiguity, disagreement, and corporate control," Technical Report, Working Paper, University of Northern Carolina, Chapel Hill 2015.

Dittmar, Amy and Anjan Thakor, "Why do firms issue equity?," The Journal of Finance, 2007, 62 (1), 1-54.

Duffee, Gregory R, "The relation between treasury yields and corporate bond yield spreads," The Journal of Finance, 1998, 53 (6), 2225-2241.

Economist, The, "Entrepreneurs anonymous," http://www.economist.com/news/business/21618816instead-romanticising-entrepreneurs-people-should-understand-how-hard-their-lives-can, 2014.

Erel, Isil, Brandon Julio, Woojin Kim, and Michael S Weisbach, "Macroeconomic conditions and capital raising," Review of Financial Studies, 2011, pp. 341-376. 
Fama, Eugene F and Kenneth R French, "Financing decisions: who issues stock?," Journal of Financial Economics, 2005, 76 (3), 549-582.

Farre-Mensa, Joan, "The Benefits of Selective Disclosure: Evidence from Private Firms," Working Paper, 2015.

Frank, Murray Z and Vidhan K Goyal, "Testing the pecking order theory of capital structure," Journal of Financial Economics, 2003, 67 (2), 217-248.

Fulghieri, Paolo, Diego Garcia, and Dirk Hackbarth, "Asymmetric information and the pecking (dis)order," Technical Report, University of North Carolina at Chapel Hill 2013.

Garmaise, Mark, "Rational Beliefs and Security Design," Review of Financial Studies, 2001, 14 (4), 1183-1213.

Geanakoplos, John, "The leverage cycle," in "NBER Macroeconomics Annual 2009, Volume 24," University of Chicago Press, 2010, pp. 1-65.

Gervais, Simon, James B. Heaton, and Terrance Odean, "Overconfidence, compensation contracts, and capital budgeting," The Journal of Finance, 2011, 66 (5), 1735-1777.

Gompers, Paul and Josh Lerner, "The venture capital revolution," Journal of Economic Perspectives, 2001, pp. 145-168.

Green, Richard C., "Investment incentives, debt, and warrants," Journal of Financial Economics, 1984, $13(1), 115-136$.

Hackbarth, Dirk, "Managerial traits and capital structure decisions," Journal of Financial and Quantitative Analysis, 2008, 43 (04), 843-881. 
Heaton, James B., "Managerial optimist and corporate finance," Financial Management, $2002,(33-45)$.

Hébert, Benjamin, "Moral Hazard and the Optimality of Debt," Available at SSRN $2185610,2014$.

Hellman, Thomas and Manju Puri, "The interaction between product market and financing strategy: The role of venture capital," Review of Financial Studies, 2000, 13 (4), 959-984.

Huang, Sheng and Anjan V Thakor, "Investor heterogeneity, investor-management disagreement and share repurchases," Review of Financial Studies, 2013, 26 (10), 24532491.

Inderst, Roman and Holger M Mueller, "Informed lending and security design," The Journal of Finance, 2006, 61 (5), 2137-2162.

Innes, Robert D, "Limited liability and incentive contracting with ex-ante action choices," Journal of Economic Theory, 1990, 52 (1), 45-67.

Kaplan, Steven N. and Per Strömberg, "Financial Contracting Theory Meets the Real World: An Empirical Analysis of Venture Capital Contracts," Review of Economic Studies, 2003, 70, 281-315.

_ and _ , "Characteristics, Contracts, and Actions: Evidence from Venture Capitalist Analyses," The Journal of Finance, October 2004, 59 (5), 2177-2210.

Koellinger, Philipp, Maria Minniti, and Christian Schade, "I think I can, I think I can": Overconfidence and entrepreneurial behavior," Journal of Economic Psychology, 2007, $28(4), 502-527$. 
Landier, Augustin and David Thesmar, "Financial contracting with optimistic entrepreneurs," Review of Financial Studies, 2009, 22 (1), 117-150.

Malmendier, Ulrike, Geoffrey Tate, and Jon Yan, "Overconfidence and early-life experiences: the effect of managerial traits on corporate financial policies," The Journal of Finance, 2011, 66 (5), 1687-1733.

_, _, and Jonathan Yan, "Corporate financial policies with overconfident managers," Technical Report, National Bureau of Economic Research 2007.

Manove, Michael and A Jorge Padilla, "Banking (conservatively) with optimists," The RAND Journal of Economics, 1999, pp. 324-350.

Marsh, Paul, "The choice between equity and debt: An empirical study," The Journal of Finance, 1982, 37 (1), 121-144.

Marx, Leslie M, "Efficient venture capital financing combining debt and equity," Review of Economic Design, 1998, 3 (4), 371-387.

McLean, R David and Mengxin Zhao, "The business cycle, investor sentiment, and costly external finance," The Journal of Finance, 2014, 69 (3), 1377-1409.

Modigliani, Franco and Merton H Miller, "The cost of capital, corporation finance and the theory of investment," The American economic review, 1958, pp. 261-297.

Myers, Stewart C, "The capital structure puzzle," The Journal of Finance, 1984, 39 (3), $574-592$.

_ and Nicholas S Majluf, "Corporate financing and investment decisions when firms have information that investors do not have," Journal of Financial Economics, 1984, 13 (2), 187-221. 
Nachman, David C and Thomas H Noe, Design of securities under asymmetric information, College of Management, Georgia Inst. of Technol., 1990.

_ and _ , "Optimal design of securities under asymmetric information," Review of Financial Studies, 1994, 7 (1), 1-44.

Noe, Thomas H, "Capital structure and signaling game equilibria," Review of Financial Studies, 1988, 1 (4), 331-355.

Oyer, Paul and Scott Schaefer, "Why do some firms give stock options to all employees?: An empirical examination of alternative theories," Journal of Financial Economics, 2005, $76(1), 99-133$.

Puri, Manju and David T Robinson, "Optimism and economic choice," Journal of Financial Economics, 2007, 86 (1), 71-99.

Schmidt, Klaus M., "Convertible Securities and Venture Capital Finance," The Journal of Finance, 2003, 58 (3), 1139-1166.

Shleifer, Andrei, Nicola Gennaioli, and Yueran Ma, "Expectations and Investment," NBER Macro Annual, 2015.

Simsek, Alp, "Belief disagreements and collateral constraints," Econometrica, 2013, 81 (1), $1-53$.

_ , "Speculation and risk sharing with new financial assets," Quarterly Journal of Economics, 2013, 128 (3), 1365-1396.

Stein, Jeremy C., "Convertible bonds as backdoor equity financing," Journal of Financial Economics, 1992, 32 (1), 3 - 21. 
Thakor, Anjan V and Toni M Whited, "Shareholder-manager disagreement and corporate investment," Review of Finance, 2011, 15 (2), 277-300.

Vallée, Boris, "Call me maybe? The effects of exercising contingent capital," Working Paper, 2013.

Winton, Andrew and Vijay Yerramilli, "Entrepreneurial finance: Banks versus venture capital," Journal of Financial Economics, 2008, 88 (1), 51-79.

Yang, Ming, "Optimality of debt under flexible information acquisition," Available at SSRN 2103971, 2013.

_ and Yao Zeng, "Financing Entrepreneurial Production: Security Design with Flexible Information Acquisition," Working Paper, 2015. 